\title{
STUDIES ON THE INTERRELATIONSHIPS OF ZOOPLANKTON AND PHYTOPLANKTON
}

\author{
By Richard Bainbridge
}

\begin{abstract}
Department of Zoology and Comparative Anatomy, University of Oxford, and Department of Zoology, University of Cambridge
\end{abstract}

\author{
(Plate I and Text-figs. I-4)
}

\begin{tabular}{|c|c|c|c|c|c|c|c|c|}
\hline \multicolumn{9}{|c|}{ CONTENTS } \\
\hline \multicolumn{9}{|c|}{ ( } \\
\hline Introduction & . & . & . & . & . & . & . & 385 \\
\hline Apparatus and methods & . & . & . & . & . & . & . & 388 \\
\hline Horizontal experiments & . & . & . & . & . & . & . & 388 \\
\hline Vertical experiments & . & . & $\because$ & . & . & . & . & 390 \\
\hline Culture of phytoplankton & 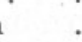 & . & i. & $\therefore$ & . & & . & $39 \mathrm{I}$ \\
\hline Exploratory toxicity exper & riment & ts (with re & esults) & & . & & . & 392 \\
\hline Treatment of the results & . &. & . & . & . & & . & 395 \\
\hline Experimental results & . & . & . & . & . & & . & 396 \\
\hline The horizontal apparatus & . & . & . & . & . & & . & 396 \\
\hline The vertical apparatus & . & . & . & . & . & & . & $4{ }^{13}$ \\
\hline Underwater observations & & . & . & . & . & & ${ }^{\circ}$ & 426 \\
\hline General discussion & . & . & . & . & . & & . & 428 \\
\hline Experiments in the horizc & ontal a & apparatus & : & . & . & ${ }^{\circ}$ & . & 428 \\
\hline Experiments in the vertic & cal app & aratus & . & . & . & . & . & 431 \\
\hline The size of plankton conc & centrat & tions. & . & . & . & . & . & 432 \\
\hline The density of phytoplan & akton $\mathrm{c}$ & concentrat & tions & . & . & . & . & 434 \\
\hline Conclusions . & . & . & . & . & . & . & . & 435 \\
\hline Summary . & . & . & . & . & . & . & . & 442 \\
\hline References . & & . & . & & $\bullet$ & . & . & 443 \\
\hline Appendix I. List of phytop & plankto & on organis & $\operatorname{sms}$ us & & . & 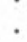 & . & 446 \\
\hline Appendix II. List of zoopl & ankton & organisn & $m s$ & & . & - & - & 447 \\
\hline
\end{tabular}

\section{INTRODUCTION}

It has in the past been thought that the marine plankton is more or less uniformly distributed. With more and more intensive sampling and observation, however, it has become apparent that the distribution of all forms of both animal and plant plankton is uneven in the extreme. Further, it has been demonstrated that generally, but by no means always, there is an inverse relationship between the quantities of zooplankton and phytoplankton taken in any one limited area. Attention was first strongly focused on this fact by Hardy (Hardy \& Gunther, 1935), although earlier authors had remarked on its occurrence. Almost simultaneously, at that time, two hypotheses were put forward to account for this phenomenon.

Harvey (1934, and more fully in the joint paper of Harvey, Cooper, Lebour \& Russell, I935), recorded occurrences of the inverse relationship in the English Channel and proposed that grazing by the zooplankton could adequately 
account for the observations. His hypothesis suggests that, in areas of high zooplankton concentrations, most of the phytoplankton would be grazed down; while in areas of low zooplankton concentration it would flourish. The effect of this would be to produce the observed inverse relationship.

Hardy (loc. cit.) showed how his own Antarctic results substantiated earlier records by Pearcey, Castracane and others of the inverse relationship, and proposed the hypothesis of 'animal exclusion' to explain it. This hypothesis supposes that high concentrations of phytoplankton are in some way 'distasteful' to plankton animals, which, during their diurnal vertical migrations, either refrain from coming up or come up for a much shorter time in areas rich in phytoplankton. The differing speeds and directions of currents at various levels then automatically segregate the concentrations of animals and plants and produce the observed inverse geographical distribution.

Both authors acknowledge that their hypotheses are not mutually exclusive and agree that either may be operative at any one time depending upon the circumstances. The possibility that a pattern may first be imposed upon the phytoplankton by grazing and may then be maintained by exclusion of the animals from the resulting areas of increasing phytoplankton density is mentioned by Hardy (p. 3ro).

The conception of a direct 'lethal' effect of phytoplankton concentrations upon zooplankton has been developed particularly by Lucas (I936, I947). Such an effect could result in an exclusion without the mediation of vertical migration and could account for those occurrences of the inverse relationship in shallower waters where phytoplankton concentrations may reach right to the bottom, as in the North Sea. There is now considerable evidence (most usefully collated by Brongersma-Sanders, I948) on the toxic properties of blooms of coloured water, but it seems likely that this is a specialized phenomenon restricted to certain species and localities. The possibility of a less marked, but nevertheless adequately operative lethal effect amongst other members of the phytoplankton, must, however, be borne in mind. Lucas (I949) has in fact drawn together much evidence on the importance of the external secretions of both animals and plants in the communal life of many organisms, and now looks upon 'animal exclusion' as one manifestation of a widespread system of ecological inter-relationships, which embraces both beneficial and harmful effects on the part of various reactants.

Steemann Nielsen (1937), while not minimizing the possible effect of grazing, maintains that the naturally different rates of development of phytoplankton and zooplankton populations are sufficient to account for the inverse relationships. Under favourable conditions a phytoplankton maximum can develop rapidly while a zooplankton maximum must necessarily lag behind. This and the frequent occurrence of phytoplankton concentrations in areas of up-welling water, which generally has a low zooplankton stock, combine to make phytoplankton and zooplankton concentrations occur in different regions. 
There is yet little evidence unequivocally in support of any of these hypotheses. Mathematical work by Fleming (I939) and observations on rates of feeding by Fuller (I937) and Gauld (I95I), among others, make it clear that Harvey's idea of grazing is well within the realms of probability. Lucas's (I936) work on zooplankton distribution in partially shaded diatom cultures, and Hardy \& Paton's (1947) work have not produced the looked for evidence in support of the exclusion hypothesis.

Any attempt to resolve between the ideas of grazing and exclusion, or to determine which may be the more important, must necessarily include an experimental approach. The present steady accumulation of data on distribution can only substantiate the existence of the inverse relationship, or at the very best serve as an indication of the possible means through which it arose. A most intensive survey would be needed to provide a solution to the problem in the sea itself. Essentially the problem is that of the behaviour of zooplankton in the presence and in the absence of phytoplankton. If the whole phenomenon arises through mechanical means (Harvey or Steemann Nielsen), then there need not be special behavioural characteristics, while if it arises through an exclusion mechanism it should be possible to demonstrate, in the laboratory, those patterns of behaviour which result in the observed distributions.

Lucas (1936) interprets his results as showing an avoidance by animals of illuminated, active, phytoplankton. Elimination of the confusing effects of shading in this work is made possible by the technique of producing a gradient of phytoplankton in a long tube (Bainbridge, I949). If animals introduced into this were to show any avoidance of high phytoplankton concentrations, then support for Hardy's hypothesis would be obtained, while if they fed blindly, remaining in even the highest concentrations of phytoplankton, then Harvey's hypothesis would be supported.

Hardy's hypothesis utilizes only the powers of vertical migration of zooplankton combined with water movements, and it would therefore be most desirable to investigate the movement of zooplankton in vertical gradients. The practical difficulties of preparing stable vertical gradients and of introducing animals into them are, however, considerable and this method of approach was rejected. Instead, the vertical migrational behaviour of animals in the presence and absence of phytoplankton in simple vertical tubes was studied. It is generally maintained that members of the plankton possess negligible powers of horizontal migration and make extensive journeys only in the vertical plane. ${ }^{1}$ I believe this view to be erroneous and am led by experimental data and observation to the conclusion that those animals now

\footnotetext{
1 The term 'zooplankton' is a very broad one covering what is not in fact a distinct group but rather a loose assemblage of animals with clearly graded powers of locomotion. Recent work (Hardy \& Bainbridge, I95I) has shown that many of these animals can in fact swim much faster and for more sustained periods than has previously been thought. It is known that almost all perform great vertical migrations but any horizontal component there may be in their movements is generally thought to be random and undirected.
} 
broadly grouped as planktonic fall naturally into two classes: one comprising most of the copepods, coelenterates, smaller and early larval stages, etc., which, if migrating at all, in fact only migrate vertically; and the other comprising some large copepods, the euphausids, mysids and cumaceans and larger larvae, etc., which, besides migrating vertically, can, and under suitable stimuli do, make horizontal migrations extensive enough to be of great consequence in the ordering of distribution. The experiments here described cater for these two classes of animals, the vertical tubes for the former and the horizontal tubes for the latter, while the results obtained serve to support the reality of this grouping.

I am deeply indebted to Professor A. C. Hardy, F.R.S., for his constant interest in this work and for having allowed me to do part of it while employed by him with a grant from the Leverhulme Trustees; to the Royal Society whose generous grant from the Browne Fund allowed it to be completed; to the Directors of the Plymouth and Millport Laboratories who most kindly provided facilities; to Messrs Siebe, Gorman and Co., who made a loan of diving equipment; and to Dr T. J. Hart and Dr C. E. Lucas for their helpful criticisms of the manuscript. Finally, I have been encouraged and advised by many friends, to all of whom I am most grateful. Most of the work described has been approved by the University of London for award of the degree of Ph.D.

\section{Straight Apparatus}

Apparatus AND Methods

\section{Horizontal Experiments}

Preliminary horizontal experiments were performed in the glass apparatus described in Bainbridge (I949). This apparatus was eventually replaced by one constructed entirely of Perspex. With this material it was possible to build up a tube of rectangular cross-section, thus eliminating those optical effects of a cylindrical tube which make the counting of small animals difficult and inaccurate. The second apparatus consists (Pl. I A, B) of a horizontal Perspex tube 48 in. long of internal dimensions $I$ in. wide by $\frac{3}{4}$ in. deep. This is divisible into four equal water-tight compartments by sliding doors; funnels at the outer ends of the outer two compartments and at the centres of the two central ones allow for filling and the introduction of animals. Two of these pieces were made so that control or replicate experiments could be performed simultaneously.

In a typical experiment the central door is first closed and the apparatus filled: freshly taken ordinary sea water (hereafter referred to as 'normal'), or filtered sea water, being put into one side and water enriched with phytoplankton into the other. After a pause of 3 or 4 minutes to allow currents to cease, the central door is opened. Diffusion and mixing of the phytoplankton and normal water follows fairly quickly and within 5 minutes a visible 

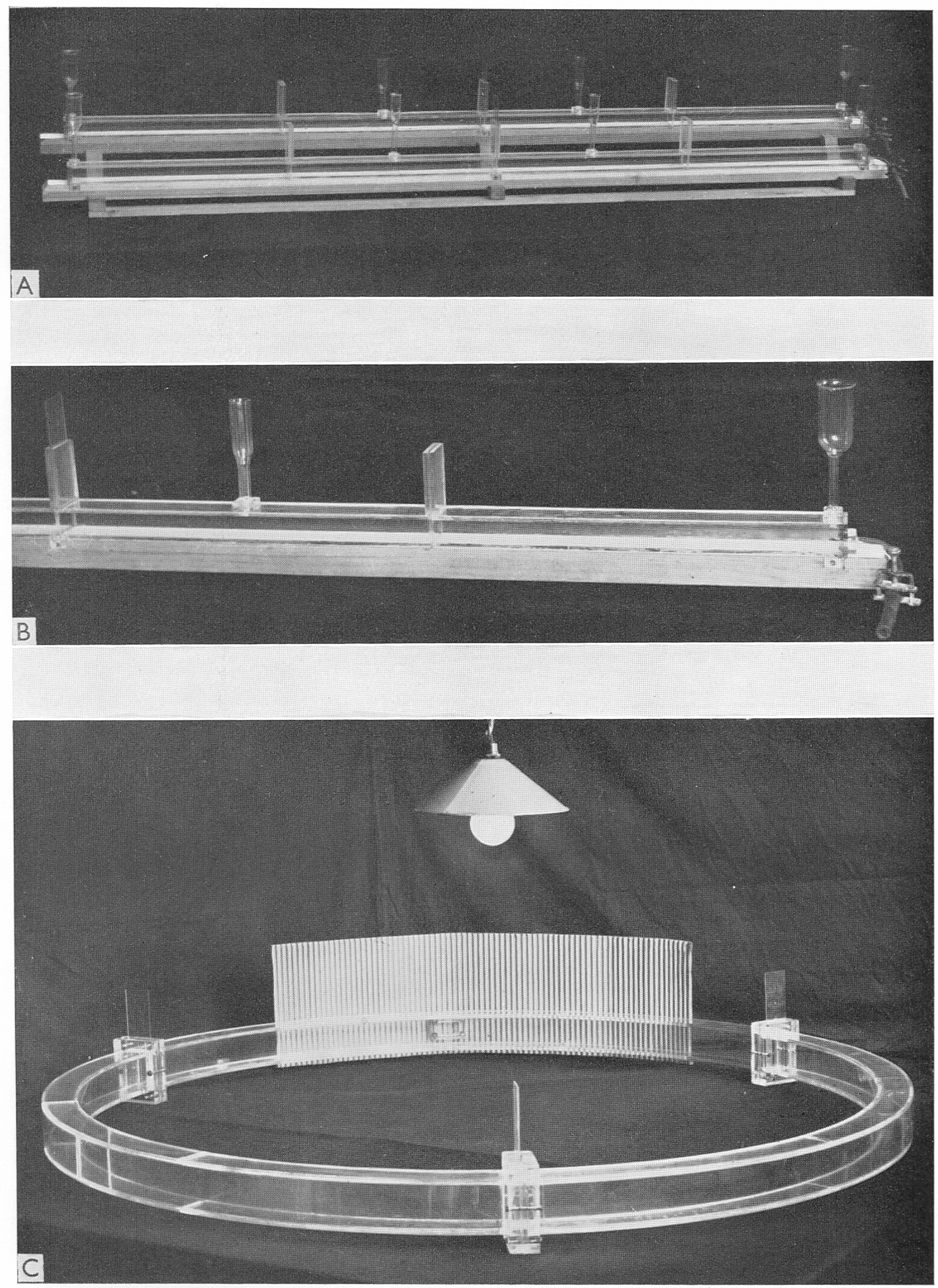

A. General view of second Perspex horizontal apparatus.

B. Detail of right-hand half of one tube of above.

C. Perspex horizontal circular apparatus, showing the three sliding doors, one section of a surrounding cardboard shield and the electric light. 
gradient of phytoplankton exists in the central Io in. or so of the tube, separating the clear water at one énd from the slightly cloudy, enriched water at the other. For a satisfactory uneven distribution to be maintained it is necessary for the waters put into the two sides of the apparatus to be identical in temperature and specific gravity. Otherwise flowing occurs and results in the formation of two layers along the length of the tube. The enriched water is always of a lower specific gravity than sea water owing to the addition of a small amount of tap water during the preparation of the culture solution (see below, p. 39r). Immediately before the experiment, therefore, the two lots of water to be used, after having been brought to the same temperature, are tested with a hydrometer and the specific gravity of the higher is brought down to that of the lower by the addition of drops of tap water. With the apparatus full, animals are pipetted into each side of it in equal numbers through the two central funnels. The distribution of animals throughout the length of the tube is now recorded at regular intervals. For this purpose the tube is divided into imaginary quarters delimited by the central door and the two outer doors. At the appropriate time the number of animals in each quarter is counted quickly and recorded in a table, When using the second apparatus, if a large number of quickly moving animals is involved, then all three doors are closed during the counting, which is thus carried out much more accurately. The doors are opened again to allow the experiment to continue.

Recording continues for the duration of the experiment and this varies from I or $2 \mathrm{hr}$. up to 3 days. During this time notes are made as to the stability of the uneven distribution in the tube and of the gradient. The simple criterion taken for the persistence of these is their continued visibility. This method is not always practicable, however, and in some instances water has to be removed from both ends by a pipette and the phytoplankton content assessed by counting. At the completion of an experiment the apparatus is emptied through the draining tube fitted at one end and is washed out. Occasionally a more thorough cleaning is required. The ends are then removed and the tube pulled through with a wad of cotton-wool on a string.

\section{Circular Apparatus}

One of the disadvantages of the straight apparatus is that animals consistently swimming in one direction come sooner or later to the end of the tube. If they have no reaction for turning and exploring in the opposite direction then they may continue swimming and butting into the end of the tube in an environment in which they would not have remained had they been able to sample that at the other end. To obviate this disadvantage some experiments were performed in a circular horizontal tube.

This apparatus (Pl. IC) consists of a Perspex tube $\mathrm{I} 2 \mathrm{ft}$. long and 2 by $\mathrm{I} \frac{1}{2}$ in. internal dimensions, built up in the form of a circle $4 \mathrm{ft}$. in diameter. 
The whole is divisible into three equal sections by sliding water-tight doors, and openings $I \frac{1}{2}$ by $\frac{1}{2}$ in. at these three points allow for filling and the introduction of animals. The apparatus is set up horizontally in a darkened constant-temperature room and illuminated by a $25 \mathrm{~W}$. electric bulb suspended symmetrically about $2 \mathrm{ft}$. above it.

In a typical experiment two of the doors are closed and the segment between them is filled with water enriched with phytoplankton. The remaining two segments are filled with normal or filtered water and, after a pause, the doors are opened. Animals are introduced in equal numbers at the three openings. For the purpose of counting the whole tube is divided into imaginary sixths, three of the boundaries coinciding with the sliding doors and three placed symmetrically between them. Starting from a fixed reference point in relation to the room the animals in successive sixths are counted quickly and the numbers recorded in a table. This is repeated at intervals for the duration of the experiment. At its completion water is drawn out at the three openings and counts of the phytoplankton made to assess the stability of the uneven distribution in the tube.

\section{Vertical Experiments}

The vertical experiments were performed in an apparatus consisting of two parallel Perspex tubes 48 in. long and 2 by $\mathrm{I} \frac{1}{2}$ in. internal dimensions. The tubes are held 2 in. apart by Perspex spacers and are closed at the top and bottom by removable Perspex covers. In the centre of each is a butterfly valve of I mm. thick Perspex which, in the horizontal position, divides the tube into upper and lower portions and, in the vertical position, presents only a very small obstacle to the movements of the animals. The valves are worked by levers, weights and strings.

In a typical experiment one tube is filled with normal or filtered water and the other with water enriched with phytoplankton. A number of animals are introduced into the top of each tube and the lids are bolted down. (The animals may be picked out and counted before use, when equal numbers are put into each tube; or roughly equal numbers may be poured in and, at the completion of the experiment, removed by filtration and counted at leisure.) The apparatus, when filled, is lowered to 6 in. below the surface of the water in the centre of a large $(72 \times 33 \mathrm{ft}$.) open tank and suspended, with the valves open, from a wooden boom. At intervals the doors are closed, the apparatus removed from the water and the number of animals in each of the upper compartments is counted and recorded in a table. The apparatus is then lowered back into the water and the doors opened. This is continued for the duration of the experiment, which may be from a few hours to several days.

Preliminary experiments were performed in this apparatus, but it soon became clear that the method had several disadvantages. First, rather small numbers swam up during the daytime owing to the high intensity of light 
and this made assessment of any difference between the two tubes difficult; and secondly, the animals were undoubtedly disturbed when the apparatus was taken out of the water and when wind caused it to move about. To obviate these disadvantages the later and main series of experiments was performed indoors in an aquarium tank.

The apparatus was suspended close to the glass of a $4 \times 4 \times 5 \mathrm{ft}$. tank with the tops of the tubes just above water-level. Lighting was oblique and chiefly from above and the intensity was a good deal less than that out of doors. The water circulating in the tank kept the apparatus at a temperature only a few degrees above that in the sea and the animals could be counted readily through the glass without any disturbance whatsoever. As a result of this it became unnecessary to close the doors, and these were removed and the apparatus split up to give two pairs of simple vertical tubes, each $2 \mathrm{ft} . \times 2$ in. $\times I_{2}^{\frac{1}{2}}$ in. This enabled duplicate readings to be taken in every experiment.

\section{Culture of Phytoplankton}

Almost all the phytoplankton organisms used in the experiments were grown in pure cultures. Occasionally natural sea water at the time of a rich diatom outburst was used, and occasionally natural water was concentrated by filtration and the concentrate used. The cultures were first grown in jars of sea water enriched with Miquel solutions and sterilized by heating to $70^{\circ} \mathrm{C}$. after Allen \& Nelson's (I9IO) instructions. More satisfactory results, however, were obtained by a modification of the 'Erdschreiber' technique, and in the bulk of the work only cultures grown in this manner were employed.

A soil extract was made by bringing a mixture of $500 \mathrm{~g}$. of garden soil and I 1. of tap water to the boil and allowing to simmer for $40 \mathrm{~min}$. This mixture was left to stand for a few days and the supernatant liquid was decanted, brought to the boil, and again left for a few days. This process of decantation and boiling was continued until a clear sherry-coloured liquid resulted. The sea water used for growing the cultures was filtered through coarse filterpaper, sterilized by heating to $70^{\circ} \mathrm{C}$., and allowed to cool. For every litre of sea water $50 \mathrm{ml}$. of the clear soil extract were brought to the boil and $0.3 \mathrm{~g}$. of sodium nitrate and $0.03 \mathrm{~g}$. of sodium hydrogen phosphate dissolved in the hot liquid. This hot solution was then added to the cold sea water and the whole stirred. After standing for a day the enriched sea water was ready for use as culture solution.

The cultures were grown variously in flasks and breffit jars standing in a window with a north light. Most of the diatoms were picked out from seawater samples that had been enriched by the addition of an equal volume of culture solution and allowed to stand for a week or so. This ensured that only healthy, growing cells were taken. Dense cultures grown from a single cell or chain of cells were obtained in this manner. The author is deeply indebted to Dr Mary Parke who provided initial samples of all the flagellates used. These 
had themselves previously been picked out by the method described, although many had been in culture for some time.

\section{Exploratory Toxicity Experiments (with Results)}

The horizontal experiments are generally lengthy to perform and use large volumes of culture. It soon became apparent, when all the early experiments were giving positive migrations into the cultures, that if any were to be found producing a reverse 'exclusion' effect, then some quicker method must be used to give a preliminary indication of cultures that might produce this effect. A series termed the 'toxicity experiments' was therefore set up in order to test cultures before use in the horizontal experiments.

A number (generally twelve) of $50 \mathrm{ml}$. capacity jars with open tops were arranged on black paper trays. $20 \mathrm{ml}$. of the culture to bé tested, either as grown or sometimes diluted with ultra-filtered water, was put into each jar and the concentration of cells assessed by counts on a haemocytometer slide. The animal chosen was Hemimysis lamornae and one of these was put into each jar and the whole batch covered with a glass plate. The animals were examined from time to time for a period of 3 days and notes were made of any that died, of the presence or absence of faecal pellets, food in the gut and other relevant observations. The trays stood on a bench in front of a window with a north light. No attempt was made to control the temperature.

The results of these experiments are summarized in Table $\mathrm{I}$, where it is seen that a total of sixty-eight different pure cultures of phytoplankton organisms was used. Control experiments, with normal sea water passed through a Berkefeld filter candle and containing no particulate matter, were used as a reference. The mean result for ten experiments with filtered water, each using twelve animals, is a total of $5 \cdot 3$ dead out of 12 at the end of 3 days. It will be seen that the great bulk of the cultures used gave a much better survival than this. Out of a total of seventy-one cultures tested (including three duplicates) twenty-four gave a complete survival and sixty-five gave five or less dead. These have all been assumed lacking in toxic properties although they may, of course, have very different nutritive values. Three cultures-Flagellate I2; Gymnodinium I and Flagellate One-each gave eight dead, Chlorella stigmatophora eleven dead, and Gymnodinium II twelve dead. These five have been suspected of having toxic properties of some kind.

In an attempt to demonstrate more clearly that these deaths were due to a toxic action and not to starvation, Chlorella stigmatophora was chosen for a series of experiments identical with those above, save that various concentrations of Chlorella were used. The results obtained from sixteen batches of jars (one with twenty-five jars, three with eight and the remainder with twelve jars) containing cultures ranging from $\mathrm{I} 3, \mathrm{I} 20$ cells $/ \mathrm{mm} .^{3}$ down to 585 cells are shown in Text-fig. IA. The concentrations have been divided into five groups, the number of jars in each group adjusted to be the same, 
TABLE I. Results of Exploratory ToXicity Experiments

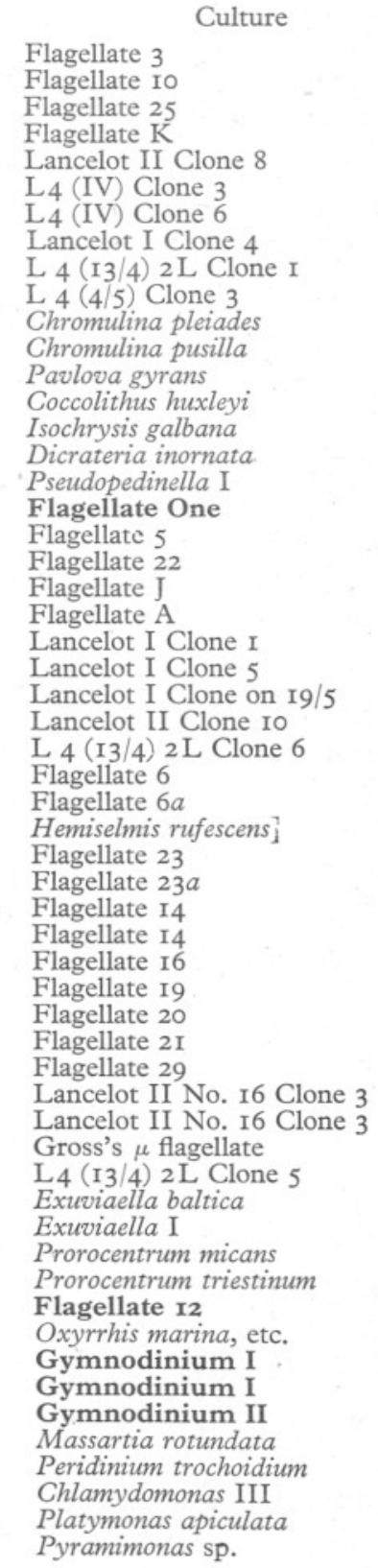

\begin{tabular}{|c|c|c|c|c|c|}
\hline & & & ber ot & $12 \mathrm{de}$ & \\
\hline & $\begin{array}{l}\text { ncentration } \\
\text { cells } / \mathrm{mm}^{3} \text { ) }\end{array}$ & $\begin{array}{c}\text { Ist } \\
24 \mathrm{hr} \text {. }\end{array}$ & $\begin{array}{l}\text { 2nd } \\
24 \mathrm{hr} .\end{array}$ & $\begin{array}{l}3 \mathrm{rd} \\
24 \mathrm{hr} .\end{array}$ & Total \\
\hline & 2,310 & - & I & - & I \\
\hline & 900 & I & 一 & I & 2 \\
\hline & 655 & - & I & I & 2 \\
\hline & 3,760 & - & - & 5 & 5 \\
\hline & 200 & - & - & I & I \\
\hline & 310 & - & - & 2 & 2 \\
\hline & 410 & I & - & - & I \\
\hline & 905 & - & - & I & I \\
\hline & $I, 480$ & - & - & - & 一 \\
\hline & 610 & I & 2 & - & 3 \\
\hline & 3,220 & I & - & - & I \\
\hline & 37,000 & - & - & - & - \\
\hline & 820 & - & - & - & - \\
\hline & 2,080 & 2 & - & - & 2 \\
\hline & 3,680 & - & - & - & - \\
\hline & II, 220 & I & - & I & 2 \\
\hline & 230 & -- & - & - & - \\
\hline & 680 & I & 4 & 3 & 8 \\
\hline & 2,120 & I & - & - & I \\
\hline & 8,800 & - & - & I & I \\
\hline & 2,640 & I & I & - & 2 \\
\hline & I, 600 & - & 一 & - & - \\
\hline & 1,760 & - & I & - & I \\
\hline & 830 & - & 3 & - & 3 \\
\hline & 1,240 & - & I & - & I \\
\hline & 2,920 & - & - & 2 & 2 \\
\hline & 2,520 & - & - & I & I \\
\hline & 820 & - & - & - & - \\
\hline & 3,840 & - & - & - & - \\
\hline & 3,440 & - & - & - & - \\
\hline & 220 & - & - & - & - \\
\hline & 36 & - & - & 2 & 2 \\
\hline & 4,320 & - & - & I & I \\
\hline & 2,860 & - & I & - & I \\
\hline & 555 & 一 & - & - & - \\
\hline & 420 & - & - & I & I \\
\hline & 230 & I & I & - & 2 \\
\hline & I 35 & - & - & - & - \\
\hline & 500 & - & - & - & - \\
\hline & 300 & I & - & - & I \\
\hline & 250 & - & - & - & 一 \\
\hline & 480 & - & - & - & - \\
\hline & 255 & I & - & 2 & 3 \\
\hline & 100 & I & I & 2 & 4 \\
\hline & 9 & I & I & I & 3 \\
\hline & I4 & - & I & I & 2 \\
\hline & 62 & - & 一 & $\overline{8}$ & $\overline{8}$ \\
\hline & 220 & - & $\overline{\mathrm{I} \cdot 5}$ & $\begin{array}{l}8 \\
\text { I.5 }\end{array}$ & 8 \\
\hline & $\begin{array}{r}2 \\
310\end{array}$ & - & $\begin{array}{l}\mathrm{I} \cdot 5 \\
\mathrm{I}\end{array}$ & $\begin{array}{l}\mathrm{I} \cdot 5 \\
\mathbf{5}\end{array}$ & $3^{6^{x}}$ \\
\hline & $\begin{array}{l}310 \\
200\end{array}$ & $\overline{3}$ & 3 & $\begin{array}{l}5 \\
2\end{array}$ & 8 \\
\hline & $\begin{array}{r}200 \\
82\end{array}$ & 1 & 9 & 3 & 12 \\
\hline 1 & 28 & - & - & 2 & 2 \\
\hline & 50 & - & I & - & $I^{\star}$ \\
\hline & I,OOO & - & - & I & I \\
\hline & II & - & - & - & - \\
\hline & 235 & - & - & - & - \\
\hline
\end{tabular}




\section{TABLE I (continued)}

\section{Culture}

Chlorella stigmatophora

Stichococcus sp.

Coscinodiscus concinnus

Skeletonema costatum

Thalassiosira gravida

Lauderia borealis

Ditylum brightwellii

Eucampia zoodiacus

Chaetoceros decipiens

Licmophora lyngbyei

Naviculoid

Nitzschia closterium (min.)

Nitzschia closterium (normal)

Nitzschia seriata

Filtered water

Filtered water

Filtered water

Filtered water

Filtered water

Filtered water

Filtered water

Filtered water

Filtered water

Filtered water

Mean of filtered results
Number out of 12 dead in

\begin{tabular}{|c|c|c|c|c|}
\hline $\begin{array}{l}\text { Concentration } \\
\left(\text { cells } / \mathrm{mm}^{3}\right)^{3}\end{array}$ & $\begin{array}{c}\text { Ist } \\
24 \mathrm{hr} .\end{array}$ & $\begin{array}{c}\text { 2nd } \\
24 \mathrm{hr} .\end{array}$ & $\begin{array}{l}3 \mathrm{rd} \\
24 \mathrm{hr}\end{array}$ & Total \\
\hline I3, I20 & 5 & 2 & 4 & II \\
\hline 570 & $\because$ & - & - & - \\
\hline $\begin{array}{l}28 t^{\circ} \\
35\end{array}$ & - & - & 二 & 二 \\
\hline I8 & I & - & 0.5 & $\mathrm{I} \cdot 5^{\star}$ \\
\hline 65 & - & 3 & - & 3 \\
\hline $\begin{array}{l}92 \mathrm{~T} \\
8\end{array}$ & 二 & 二 & $\bar{I}$ & $\bar{T}$ \\
\hline 53 & - & - & - & - \\
\hline 275 & I & - & - & I \\
\hline & $\overline{0.5}$ & $\overline{I .5}$ & I & I \\
\hline c. 400 & $\begin{array}{l}15 \\
1\end{array}$ & 15 & 2 & $\stackrel{4}{I}^{\wedge}$ \\
\hline $\begin{array}{l}73 \\
12\end{array}$ & - & - & - & - \\
\hline - & I & 8 & 3 & I2 \\
\hline 一 & I & 一 & 4 & 5 \\
\hline - & 一 & 2 & 3 & 5 \\
\hline 一 & $\overline{0}$ & 2 & 2 & 4 \\
\hline 二 & 2 & 3 & $\begin{array}{l}2 \\
I\end{array}$ & $\begin{array}{l}7 \\
\mathrm{I}\end{array}$ \\
\hline - & I & I & 6 & 8 \\
\hline - & - & 6 & - & 6 \\
\hline - & I & - & - & I \\
\hline- & - & 2 & 2 & 4 \\
\hline - & 0.6 & $2 \cdot 4$ & $2 \cdot 3$ & $5 \cdot 3$ \\
\hline
\end{tabular}

Note. The above organisms are in classificatory order as in Appendix I and not in the order of testing. Species considered toxic have been put in heavy type.

* Calculated from a total of 25 .

$\dagger$ Cells/100 mm. ${ }^{3}$.

Summary showing numbers of cultures resulting in various deaths:

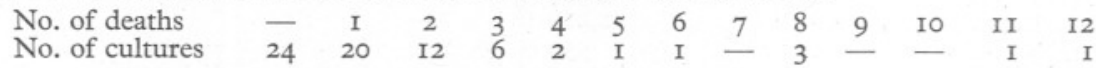

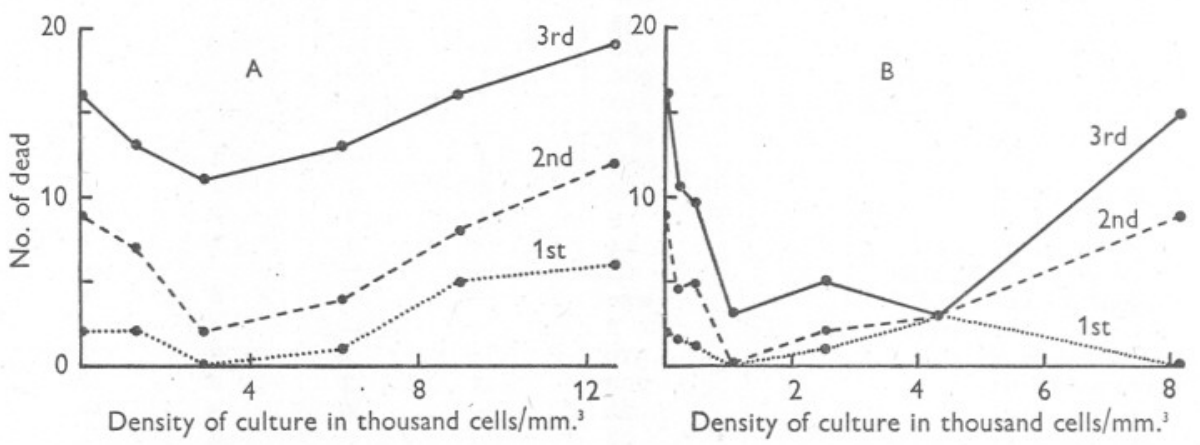

Text-fig. I. Results of toxicity experiments with cultures of various concentrations of (A) Chlorella stigmatophora, (B) Nitzschia closterium. Numbers of dead, out of thirty-two in $A$ and thirty-six in B, on the Ist, 2nd and 3 rd days. 
and the figures expressed as numbers dead per thirty-two animals after I, 2 and 3 days. It is seen that there is an optimum survival at a concentration of about 3000 cells $/ \mathrm{mm}^{3}$. Below this the increase in deaths may be assumed due to starvation and above it to the toxic effect.

Lucas (I936) has put forward evidence for an optimum survival in Nitzschia closterium cultures of a certain strength, and an attempt was made to demonstrate this with Hemimysis lamornae. The results were treated as those for Chlorella and are depicted in Text-fig. I B. It is seen that survival is generally much better than with Chlorella, except at the lowest concentrations, but that again there is an optimum at a certain concentration, this time about Iooo cells $/ \mathrm{mm}^{3}$. (This figure is higher than that found by Lucas who considered the optimum to lie between 25 and Ioo cells $/ \mathrm{mm} .^{3}$, but he used Neomysis vulgaris and the two species may well react differently.) It may again be assumed that there is some sort of toxic effect at higher concentrations. This was not recognized in the earlier 'toxicity' series of experiments because a sufficiently high concentration of cells was not used. Such a concentration would not generally be met with in nature so the result must largely be of academic interest except, perhaps, in so far as it is an indication of what may, in lesser degree, be happening at lower concentrations and not detectable by this experimental method.

\section{Treatment of the Results}

In some of the experiments the behaviour of the animals in relation to the uneven distribution of phytoplankton in the straight or in the circular horizontal apparatus is very distinctive, but in general it is necessary to apply an appropriate statistical technique in order to determine which differences in the distribution of the animals are significant.

In the straight apparatus, for any given reading, this involves calculation of the deviation for the numbers in the left- and right-hand sides of the tube. The reading is taken to be significant if this exceeds twice the value of $\sigma$ calculated for the particular number of animals in the tube. For the purpose of this work a significant difference is termed positive or negative depending upon whether it involves a movement into the phytoplankton-rich side of the apparatus or away from it.

It is not possible to apply the test for significance to more than one reading in a particular experiment and then attribute an independent and equal value to each answer, because each successive reading is to some extent dependent for its value upon those preceding it in the series. This invalidates the test used. The latter is therefore only applied to one reading in an experiment or only once to the mean of several readings. The single reading or the selection of readings averaged may be taken arbitrarily or may be chosen as typical of the experiment as a whole. 
In the circular experiments the results are treated similarly. The numbers in the six sections counted cannot however be divided symmetrically about the third of the tube containing the enriched water. The number in the phytoplankton third is therefore compared with the number in the third opposite it across the circle and the numbers in the two sixths between these sectors are disregarded. This is a more rigorous test than the simple comparison of halves and in some border-line cases special counts were made of the two halves. The dividing line was then that diameter at right angles to the one passing symmetrically through the phytoplankton third. This special count was most valuable when there had been more than the normal spreading of the phytoplankton sector and parts of the disregarded sixths were rich in both phytoplankton and zooplankton.

In the vertical experiments such changes as occur in the vertical migrational behaviour in the two tubes have again to be treated mathematically in order to determine whether they differ significantly from expected chance variations. The test employed in this case is a test of independence and is applicable because the data fit a two by two table. The factor $\chi^{2}$ is calculated for the reading to be tested and if it exceeds $3.84 \mathrm{I}$ then the difference in distribution in the two tubes is taken as significant. Again only one reading or the mean of several readings may be tested in this manner.

If, as in most of the experiments, the difference between the numbers swimming up in the pair of tubes is too small to satisfy this test for significance, it is possible to lump together the single readings from each one of a series of comparable experiments and perform the test on these larger figures. Reliance can only be placed on this 'pooled result' if the data are shown independently to satisfy a test for homogeneity.

\section{EXPERIMENTAL RESULTS}

\section{The Horizontal Apparatus}

The results of three typical experiments in the straight horizontal apparatus are given in Tables II-IV. The first comprises the first day's readings in a control experiment having both tubes uniformly filled with water freshly taken from the Plymouth Laboratory circulation ('tank water') and with ten Hemimysis lamornae introduced into each side of both tubes at I2.00 hr. It is seen that the distribution remains fairly uniform, and although two readings (I2.30 and $\mathrm{I} 3.00 \mathrm{hr}$. in tube II) show a significant departure from normality this is not maintained. Such significant clumpings in a uniform tube are referred to later.

Table III gives the readings in an experiment with water rich in the flagellate Rhodomonas sp. in the left-hand side of one tube and ultrafiltered water in the right-hand side; and Rhodomonas in the right-hand side of the other and ultrafiltered water in the left. Ten Hemimysis lamornae, previously 
fed on diatoms and flagellates, were introduced into each side of both tubes at IO.I5 hr. An immediate movement away from the flagellates occurred and this was maintained for the duration of the experiment.

\section{TABle II. Experiment DHT 30 (II March I952)}

(Two horizontal tubes set up as described. Both completely filled with fresh tank water. Ten Hemimysis lamornae put in each side of both. Just taken from the aquarium tanks.)

\begin{tabular}{|c|c|c|c|c|c|c|c|c|}
\hline \multirow{3}{*}{$\begin{array}{l}\text { Time } \\
\text { (hr.) } \\
\text { I2.00 }\end{array}$} & \multicolumn{4}{|c|}{1} & \multicolumn{4}{|c|}{ II } \\
\hline & \multicolumn{2}{|c|}{ Normal } & \multicolumn{2}{|c|}{ Normal } & \multicolumn{2}{|c|}{ Normal } & \multicolumn{2}{|c|}{ Normal } \\
\hline & - & IO & I0 & - & - & IO & IO & - \\
\hline 12.30 & 8 & I & I & IO & 4 & I & 2 & I3 \\
\hline I3.00 & 7 & I & I & II & 5 & 一 & 4 & II \\
\hline I 4.30 & 8 & 2 & 2 & 8 & 8 & 2 & 3 & 7 \\
\hline 16.00 & 8 & I & 3 & 8 & I 2 & - & I & 7 \\
\hline I 7.30 & 8 & 2 & 3 & 7 & II & 4 & I & 5 \\
\hline 19.00 & 8 & 3 & 2 & 7 & IO & 4 & 2 & 4 \\
\hline 20.30 & - & I2 & 7 & I & I & II & 7 & I \\
\hline
\end{tabular}

\section{TABle III. Experiment DHT 3 I (I3 March I952)}

(Two horizontal tubes set up as described. I, Rhodomonas sp. culture in L.H.s. Ultrafiltered water in R.H.S. II, ultrafiltered water in L.H.S. Rhodomonas in R.H.S. Ten Hemimysis lamornae put in each side of both. Previously fed on a mixture of diatoms and flagellates.)

I

\begin{tabular}{ccccc} 
Time & \multicolumn{2}{c}{ A } & B & \multicolumn{2}{c}{ C } & D \\
(hr.) & \multicolumn{2}{c}{ Rhodomonas } & \multicolumn{2}{c}{ Normal } \\
I0.15 & - & IO & I0 & - \\
I0.30 & I & - & 7 & I2 \\
II.00 & I & - & 7 & I2 \\
II.30 & I & - & 5 & I4 \\
I3.00 & I & - & 7 & I2 \\
I4.30 & I & I & 7 & II
\end{tabular}

II

$\begin{array}{lrrr}\text { A } & \text { B } & \text { C } & \text { D } \\ \text { Normal } & & \text { Rhodomonas } \\ \text { I0 } & \text { Io } & \text { IO } & \text { - } \\ \text { I0 } & 7 & 3 & - \\ \text { I4 } & 4 & 2 & - \\ \text { I5 } & 3 & 2 & - \\ \text { I3 } & 5 & \text { I } & \text { I } \\ \text { I2 } & 6 & 2 & \text { - }\end{array}$

TABLe IV. EXPeriment DHT 32 (I4 March 1952)

(Two horizontal tubes set up as described. I, Thalassiosira gravida culture in L.H.S. Ultrafiltered water in R.H.S. II, ultrafiltered water in L.H.S. Thalassiosira culture in R.H.S. Ten Praunus neglectus put in each side of both. Previously fed on a mixture of diatoms and flagellates.)

$$
\begin{aligned}
& \text { Time } \\
& \text { (hr.) } \\
& \text { II.00 } \\
& \text { I1.30 } \\
& \text { I2.00 } \\
& \text { I3.00 } \\
& \text { I4.30 } \\
& \text { I6.00 }
\end{aligned}
$$
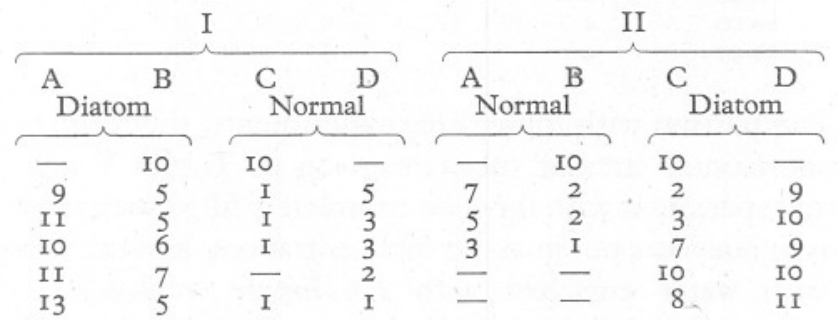

Table IV gives the readings in an experiment with water enriched with the diatom Thalassiosira gravida in one side of each of the two tubes, and filtered 
water in the other, and with ten Praunus neglectus put in each side. A marked migration is again apparent, but in this case into the enriched water and rather slower in occurrence. All but the first reading in tube I and the first two in tube II are significant.

\section{TABle V. EXPeriment HCT 4 (I6 October I95I)}

(Horizontal circular tube set up as described. Completely filled with fresh tank water. Twelve Hemimysis lamornae put in at each junction. Previously fed on Peridinium trochoidium.)

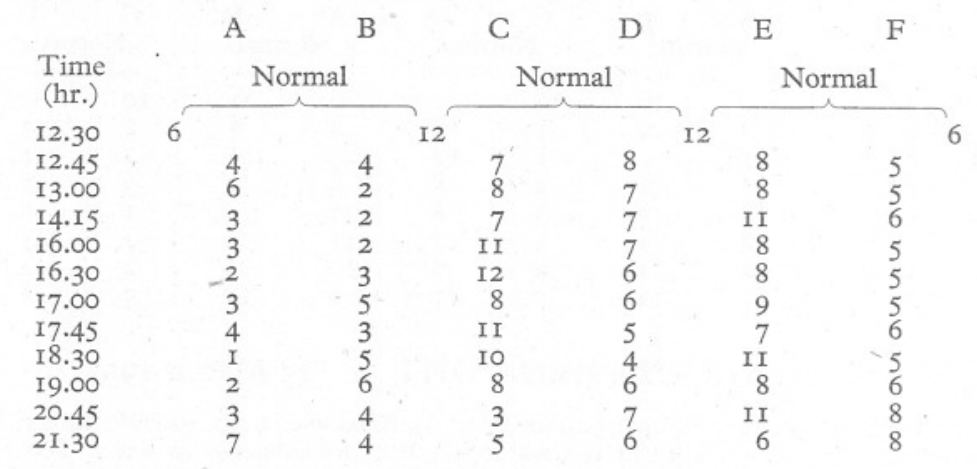

TABle VI. Experiment HCT 3 (I5 October I95I)

(Horizontal circular tube set up as described. Water rich in Peridinium trochoidium in one third. Outside water in the rest. Twelve Hemimysis put in at each junction. Starved in filtered water for the previous $4 \frac{1}{2} \mathrm{hr}$.)

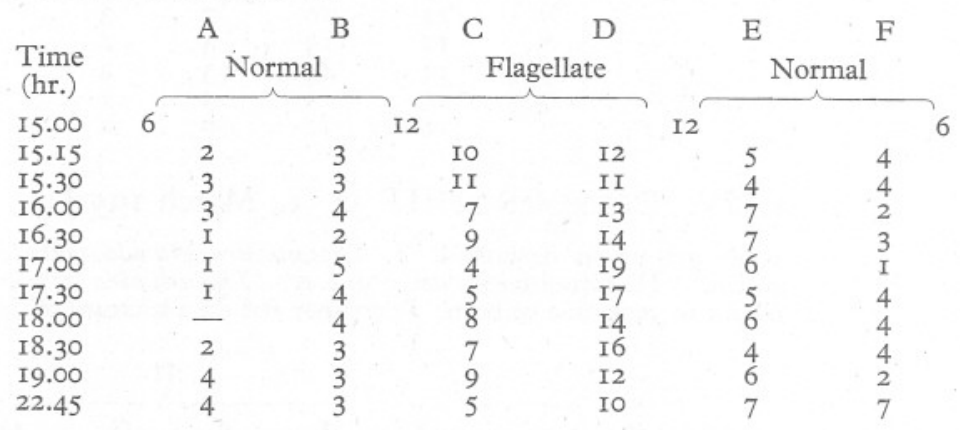

For comparison with these three experiments, the results of two performed in the horizontal circular tube are given in Tables V and VI. The first is a control experiment with the tube completely filled with tank water and twelve Hemimysis lamornae put in at the three entrances; and the second has one-third filled with water enriched with Peridinium trochoidium culture and the Hemimysis used had previously been starved in ultrafiltered water. Distribution in the control experiment in relation to sector CD departs significantly from normality in only one reading, that of $16.30 \mathrm{hr}$. In the other, however, 
a clear movement into the enriched water sector $C D$ takes place at once and is maintained for the greater part of the experiment.

These, and the remaining horizontal results, have been treated mathematically and the experiments put into one of the three categories-positive, negative, or not significant-depending upon whether a significant migration into, or away from, the phytoplankton takes place, or whether there is no significant departure from an even distribution. The experiments are classified first according to the animals used, and secondly, according to the phytoplankton organisms or the type of water. They are recorded in the following tables, together with details of the concentration of phytoplankton put in the one side of the apparatus and the state of the animal. This latter is taken as either starved or fed dependent upon whether the animals had been kept for some time in filtered water, or had been fed or just recently caught (when food is generally to be found in the gut).

The tables may best be considered according to the animals used and Hemimysis lamornae, with which the greatest number of experiments was performed, is taken first.

\section{Hemimysis lamornae}

\section{Experiments involving Diatoms}

Amongst the diatoms, clear migrations into water enriched with Skeletonema costatum, Thalassiosira gravida, Biddulphia sinensis, Nitzschia closterium and a mixed culture of diatoms were obtained. There were no negative migrations amongst these species but out of nineteen experiments performed five gave no significant result. The distribution of the positive results between fed and starved animals suggests a more marked migration by the latter, but the results do not satisfy a mathematical test for significance. Exp. DHT 5I has been disregarded, as later work showed animals to move away from ordinary water passed through the Berkefeld filter candle employed here. This is considered later (p. 407). Five experiments were performed with Lauderia borealis, of which three proved not significant, one positive and one just negative (four significant negative readings out of a total of eight). Lauderia was not used in any other experiments, but it may be that it is not particularly ácceptable to Hemimysis. There was no special indication of a lethal effect in the 'toxicity experiments'. Coscinodiscus concinnus also gave two not significant results, but more experiments would need to be performed before it could be said not to be acceptable to the animals. Excluding these two doubtful species, the summarized results with diatoms reveal a substantial majority of experiments showing a positive migration. Even including them there is only one negative migration as compared with fifteen positive in a total of twenty-six.

Two of the experiments with Skeletonema and two with Thalassiosira utilized water from a growing culture which was centrifuged in order to 
remove the bulk of the cells. Positive migrations were still obtained in three of these four cases suggesting that the attractive principle may reside in the water itself.

\section{TABLE VII. HEMIMYSIS LAMORNAE AND DiATOMS}

(In this and the subsequent tables the four columns represent: (i) the serial number of the experiment; (ii) the concentration, in cells $/ \mathrm{mm} .^{3}$, of the phytoplankton used; (iii) the state of the animal, F representing fed and S starved; (iv) the result of the experiment as a whole. If there should be insufficient significant readings to merit designating the whole experiment such, or if only a minimum number should be so, then this may be noted as e.g. ( 3 rds + ve) meaning three significant positive readings.) N.S. : not significant.

Skeletonema costatum

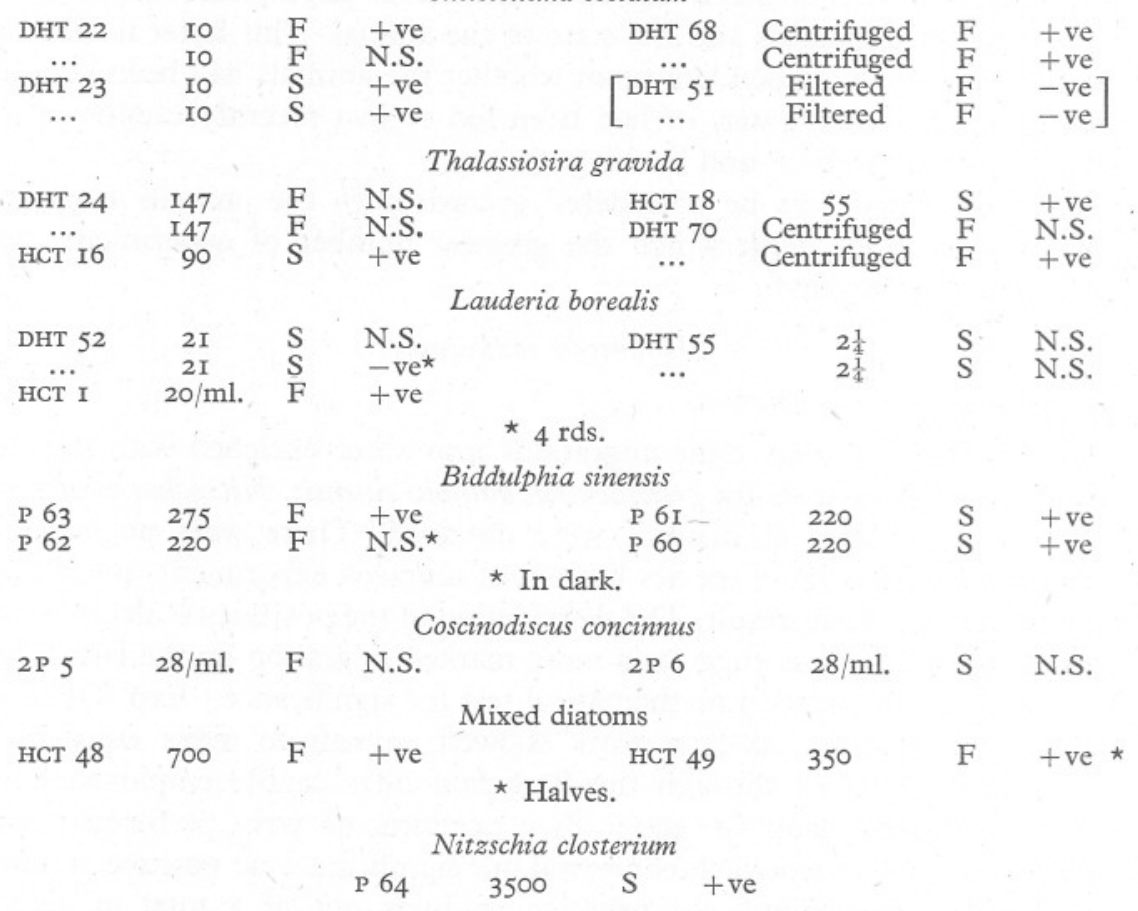

Summary distribution of results with $H$. lamornae and diatoms

\begin{tabular}{|c|c|c|c|c|c|c|c|}
\hline \multicolumn{4}{|c|}{ All species } & \multicolumn{4}{|c|}{ ria and Coscinodiscus } \\
\hline & +ve & N.S. & - ve & & + ve & N.S. & - ve \\
\hline $\begin{array}{l}\text { Fed } \\
\text { Starved }\end{array}$ & 8 & 6 & 一 & Fed & 7 & 5 & - \\
\hline Starved & 7 & 4 & I & Starved & 7 & - & - \\
\hline
\end{tabular}

\section{Experiments involving Flagellates}

The independent evidence of a possible toxic action by some of the flagellates used is taken as the basis for a division of the remaining results involving phytoplankton and Hemimysis into two groups-those involving 'toxic flagellates' and those involving 'non-toxic flagellates'. The latter will be considered first. 
As seen in Table VIII, significant migrations were obtained into concentrations of Chlamydomonas sp., Peridinium trochoidium, Pyramimonas sp., Dicrateria inornata and Flagellate K. Again a greater proportion of positive results was obtained with starved than with fed Hemimysis, but not significantly so. There was a greater number of not significant results even with the

TABle VIII. HEMIMYSis LAMORNAE AND 'Non-toxic Flagellates'

Chlamydomonas sp.

\begin{tabular}{|c|c|c|c|c|c|c|c|}
\hline & & & & & & & \\
\hline 2 P II & 520 & F & N.S. & DHT 46 & 42 & F & N.S. \\
\hline HCT 25 & 225 & F & N.S. & .. & 42 & F & N.S. \\
\hline P 30 & 170 & F & N.S. & DHT $4^{8}$ & 30 & $\mathrm{~F}$ & N.S. \\
\hline DHT 49 & II 3 & $\mathrm{~F}$ & N.S. & $\cdots$ & 30 & F & N.S. \\
\hline$\cdots_{45}$ & II 3 & F & N.S. & $2 \mathrm{P} \mathrm{I} 2$ & 520 & $\mathrm{~S}$ & $+\mathrm{ve}$ \\
\hline DHT 45 & 105 & $\mathrm{~F}$ & +ve & HCT 24 & 250 & S & +ve \\
\hline$\cdots$ & 105 & F & + ve & HCT 2 I & 235 & S & -ve \\
\hline DHT 50 & 77 & $F$ & N.S. & P 29 & I 70 & $\mathrm{~S}$ & ve \\
\hline ‥ & 77 & $F$ & N.S. & HCT 72 & 120 & $\mathrm{~S}$ & . \\
\hline $\begin{array}{l}\ldots \\
\ldots\end{array}$ & $\begin{array}{l}02 \\
62\end{array}$ & F & N.S. & DHT 53 & $\begin{array}{l}00 \\
60\end{array}$ & S & \\
\hline \multicolumn{8}{|c|}{ Peridinium trochoidium } \\
\hline DHT I & $53^{\star}$ & $\mathrm{F}$ & +ve & HCT 3 & I8 & $\mathrm{S}$ & \\
\hline DHT 2 & $28^{\star}$ & $\mathrm{F}$ & $+\mathrm{ve}$ & HCT 5 & I8 & $\mathrm{S}$ & 1 \\
\hline$\cdots$ & $28^{\star}$ & S & N.S. & & & & \\
\hline
\end{tabular}

Pyramimonas sp.

\begin{tabular}{|c|c|c|c|c|c|c|c|}
\hline DHT 4I & I39 & $\mathrm{F}$ & +ve & DHT 42 & I39 & $S$ & N.S. \\
\hline$\cdots$ & I39 & $\mathrm{F}$ & $+v e$ & $\ldots$ & I39 & $\mathrm{S}$ & N.S. \\
\hline \multicolumn{8}{|c|}{ Syracosphaera carterae } \\
\hline HCT $5 \mathrm{I}$ & 68 & $\mathrm{~F}$ & N.S. & HCT I9 & 77 & $\mathrm{~S}$ & N.S. \\
\hline HCT 70 & 8 & $\mathrm{~F}$ & N.S. & HCT 20 & 70 & $\mathrm{~S}$ & N.S. \\
\hline \multicolumn{8}{|c|}{ Exuviaella baltica } \\
\hline HCT 40 & 2 & $\mathrm{~F}$ & N.S. & DHT 2 I & $3 I$ & $\mathrm{~S}$ & N.S. \\
\hline \multicolumn{8}{|c|}{ Dicrateria inornata } \\
\hline $2 \times 4$ & 2760 & F & + ve & $2 \times 3$ & 2040 & $\mathrm{~S}$ & +ve \\
\hline $2 \mathrm{P} 2$ & 3130 & $\mathrm{~S}$ & +ve & & & & \\
\hline & \multicolumn{6}{|c|}{ Flagellate $\mathrm{K}$} & \\
\hline HCT 57 & 230 & $\mathrm{~F}$ & $+v e^{\star}$ & HCT $7 \mathrm{I}$ & IO & S & N.S.† \\
\hline
\end{tabular}

Summary distribution of results with $H$. lamornae and non-toxic flagellates

\begin{tabular}{lcccccccc}
\multicolumn{3}{c}{ All species } & \multicolumn{4}{c}{ Excluding Syracosphaera and Exuviaella } \\
& + ve & N.S. & - ve & & +ve & N.S. & - ve \\
Fed & 8 & I6 & - & & Fed & 8 & I3 & - \\
Starved & 7 & II & - & & Starved & 7 & 8 & -
\end{tabular}

starved animals, and the totals are fifteen positive results to twenty-one not significant. Four experiments with Syracosphaera carterae and two with Exuviaella baltica all gave not significant results. A 'toxicity experiment' was not performed with Syracosphaera but there was no indication of a harmful 
effect in the horizontal tubes; one performed with Exuviaella revealed no effect. It may be that these two forms fall into the same 'unacceptable' category as

\section{Table IX. Hemimysis lamornae and 'Toxic Flagellates'}

\begin{tabular}{|c|c|c|c|c|c|c|c|}
\hline \multicolumn{8}{|c|}{ Gymnodinium II } \\
\hline НСт 58 & 54 & $\mathrm{~F}$ & N.S. & DHT 69 & Centrifuged & F & $-\mathrm{ve}$ \\
\hline HCT 50 & 40 & $\mathrm{~F}$ & N.S. * & $\ldots$ & Centrifuged & $\mathrm{F}$ & - ve \\
\hline HCT 47 & 14 & $\mathrm{~F}$ & $+\mathrm{ve}$ & DHT 71 & Cent. (dil.) & $\mathrm{F}$ & - ve \\
\hline HCT 46 & 7 & $\mathrm{~F}$ & N.S. & & Cent. (dil.) & $\mathrm{F}$ & N.S. \\
\hline DHT 37 & Filtered & $\mathrm{F}$ & - ve $]$ & DHT 35 & 63 & S & N.S. \\
\hline$\ldots$ & Filtered & $\mathrm{F}$ & N.S.†] & ${ }_{2 P}{ }_{20}$ & 63 & $\begin{array}{l}S \\
S\end{array}$ & $\begin{array}{l}\text { N.S. } \\
\text { N.S. }\end{array}$ \\
\hline & * Gymno. & I. & $\begin{array}{c}+2 \\
\mathrm{Fla}\end{array}$ & & $\ddagger 3$ rds - ve. & & \\
\hline DHT I8 & 98 & $\mathrm{~F}$ & N.S.* & [DHT 36 & Filtered & $\mathrm{F}$ & $-\mathrm{ve}]$ \\
\hline & 98 & $\mathrm{~F}$ & N.S. & {$[\quad \ldots$} & Filtered & $\mathrm{F}$ & \\
\hline HCT 53 & 37 & $\mathrm{~F}$ & - ve & DHT I9 & 98 & $\mathrm{~S}$ & N.S. \\
\hline HCT 52 & I8 & $\mathrm{F}$ & N.S. & $\ldots$ & 98 & $\mathrm{~S}$ & +ve \\
\hline HCT 37 & 6 & $\mathrm{~F}$ & N.S. & DHT 20 & 98 & $\mathrm{~s}$ & N.S. \\
\hline DHT 64 & Centrifuged & $\mathrm{F}$ & N.S. & HCT 66 & 29 & S & N.S. \\
\hline$\ldots$ & Centrifuged & $\mathrm{F}$ & $+\mathrm{ve}$ & & & & \\
\hline
\end{tabular}

Oxyrrhis marina, Rhodomonas sp. and Nitzschia closterium

\begin{tabular}{|c|c|c|c|c|c|c|c|}
\hline HCT 3 I & 20.5 & $\mathrm{~F}$ & + ve & DHT 20 & 80 & S & N.S. \\
\hline HCT 56 & 16.0 & F & N.S. & DHT 25 & 60 & $\mathrm{~S}$ & - ve \\
\hline HCT 35 & 15.0 & F & N.S. & $\ldots$ & 60 & S & - ve \\
\hline HCT 33 & $12 \cdot 0$ & $\mathrm{~F}$ & N.S. & $2 \mathrm{P}$ IO & c. 4.0 & S & $+\mathrm{ve}$ \\
\hline P 33 & II.O & F & N.S. & DHT 26 & 40 & F & - ve \\
\hline P 69 & $7 \cdot 0$ & $\mathrm{~F}$ & N.S.* & $\ldots$ & 40 & F & -ve \\
\hline HCT 55 & $6 \cdot 5$ & $\mathrm{~F}$ & N.S. & DHT 27 & 23 & F & - ve \\
\hline HCT 54 & 5.5 & F & N.S. & DHT 28 & Aerated & F & N.S.† \\
\hline $2 \times 9$ & c. $4^{\circ} 0$ & F & N.S. & DHT 29 & 65 & F & +ve $\ddagger$ \\
\hline
\end{tabular}

\begin{tabular}{|c|c|c|c|c|c|c|c|}
\hline \multicolumn{8}{|c|}{ Rhodomonas only (Oxyrrhis filtered off) } \\
\hline DHT 29 & 200 & F & $-v e^{\star}$ & DHT 56 & I & $\mathrm{S}$ & -ve \\
\hline DHT $3 \mathrm{I}$ & 100 & $\mathrm{~F}$ & -ve & $\ldots$ & I & $\mathrm{S}$ & - ve \\
\hline$\cdots$ & IOO & $\mathrm{F}$ & -ve & [DHT 27 & Filtered & $\mathrm{F}$ & $-v e]$ \\
\hline \multicolumn{8}{|c|}{$\star 4$ rds. } \\
\hline \multicolumn{8}{|c|}{ Chlorella stigmatophora } \\
\hline DHT 33 & 3580 & F & + ve & DHT 34 & 3800 & S & +ve \\
\hline$\cdots$ & 3580 & $F$ & N.S. & $\cdots$ & 3800 & $\mathrm{~S}$ & N.S. \\
\hline
\end{tabular}

Summary distribution of results with $H$. lamornae and toxic flagellates

\begin{tabular}{lccc}
\multicolumn{4}{c}{ (excluding Chlorella) } \\
Fed & +ve & N.S. & - ve \\
Starved & 3 & I7 & I2 \\
& 2 & 7 & 4
\end{tabular}

Lauderia and Coscinodiscus. In none of this group of experiments was any negative migration obtained and, although there are more not significant results than positive, the positive bias is still most marked. 
The 'toxic flagellate' group comprises the two cultures of Gymnodinium (I and II) and Flagellate I2, all showing lethal effects in the toxic experiments; and the mixed culture of Oxyrrhis marina, Rhodomonas sp. and Nitzschia closterium which, although not showing a toxic effect in the weak culture used in the test experiments, afterwards showed enough harmful effects in the horizontal tubes to merit its inclusion here. The position of Chlorella is anomalous both on account of its being a non-motile chrysophycaean and because the experiments performed with it were at the optimum concentration which showed little toxic effect. The results with it are therefore considered separately.

All but one of the Gymnodinium experiments involved Gymnodinium II, the species showing the more marked toxic effect. Out of eleven experiments one gave a positive result (with fed animals) and three gave negative results. The remainder were all not significant. The positive result was obtained with a low concentration of cells and the negative results with water from a growing culture which had been centrifuged to remove most of the cells. The centrifugate used in DHT 7I, where only one of a pair was significantly negative, was previously diluted with ordinary water. The inference may be made that the repellent principle is situated in the water in which the flagellate has grown.

Of eleven results with Flagellate I2 the majority again are not significant. One is negative, involving fed animals; and two positive, one normal with starved animals and one with centrifuged water and fed animals. The latter would seem opposed to the idea of a toxic or repellent principle in the water, and in fact the form of the gut in most specimens (which fed freely) suggested some internal effect, but the evidence is rather tenuous. Unfortunately, the only cultures of Flagellate I2, which were at Plymouth, Millport and Bangor, died out at about the same time in the spring of I952. The results will, however, be followed up if it proves possible to re-establish a culture from the sea. This organism is of particular interest as it is thought to be a primitive dinoflagellate, a group which embraces the gymnodiniums, Oxyrrhis and other forms such as Goniaulax, which are known to have toxic properties.

Three positive results were obtained with the Oxyrrhis, Rhodomonas and Nitzschia culture, but ten negative ones: all out of a total of twenty-three. Oxyrrhis is not an autotrophic flagellate and can only be grown if supplied with food. This particular culture provides a large Nitzschia and the autotrophic Rhodomonas as possible food and is of long standing. The Nitzschia content fluctuates a great deal but is generally low, while most Rhodomonas cells clump into aggregations about the size of a small tea leaf, and the Oxyrrhis swims freely. The culture was used just as grown in the early experiments when both positive and negative results were obtained. These led to an attempt to separate the component parts in order to assess their individual effects, and this was found to be relatively easily done by filtering 
through fine silk. A growth was obtained with a low Nitzschia content, and after being left quiescent for some days to ensure a maximum clumping of the Rhodomonas, was passed through fine silk. Almost pure Oxyrrhis passed through and the Rhodomonas clumps were left on the silk. They were washed with culture solution and then resuspended and shaken vigorously in filtered sea water. This treatment gave a suspension containing a good many free cells. Consistent and very marked migrations away from such a suspension were obtained, while the almost pure Oxyrrhis gave a positive result. It seems clear that the variable results with the mixed culture derived from the opposing reactions to the Oxyrrhis and the Nitzschia on the one hand and to the Rhodomonas on the other. The two positive migrations with the mixed culture were both into samples with a low Rhodomonas content as compared with the Oxyrrhis.

The summary of results with the toxic flagellates shows the preponderance of negative migrations as compared with positive. These result largely from the effect of Rhodomonas and Gymnodinium II, both of which may be considered to be avoided because of their harmful properties.

Four experiments were performed with Chlorella stigmatophora at its optimum concentration for survival, two with fed Hemimysis and two with starved. One of each of these pairs showed a significant positive migration, the other being not significant.

\section{Miscellaneous Experiments}

An earlier experiment (HCT 9) used small zooplankton animals in place of phytoplankton. Some of these died and a concentration of bacteria quickly formed in the tube and was apparently avoided by the Praunus neglectus being tested. This led to a closer study of the effect of water rich in bacteria.

\section{TABle X. HEMIMYSis LAMORNAE AND BACTERIA}

\begin{tabular}{|c|c|c|c|}
\hline DHT 3 & Normal bacteria & $\mathrm{F}$ & - ve \\
\hline $\mathrm{HT}$ & Normal bacteria & $\mathrm{F}$ & $-\mathrm{ve}$ \\
\hline $\mathrm{HT} I$ & Normal bacteria & - & N.s.* \\
\hline DHT 7 & Diluted to $50 \%$ & - & - ve \\
\hline & Diluted to $50 \%$ & & - ve \\
\hline DHT 65 & Diluted to $25 \%$ & F & $-\mathrm{ve}$ \\
\hline & Diluted to $25 \%$ & $\mathrm{~F}$ & $-\mathrm{ve}$ \\
\hline & Diluted to $10 \%$ & F & N.S. \\
\hline & uted to $10 \%$ & & \\
\hline
\end{tabular}

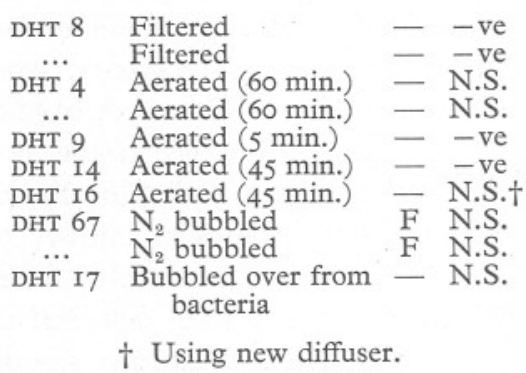

A suspension of bacteria was grown by leaving some small dead animal, such as a prawn, in a breffit of raw sea water for about $24 \mathrm{hr}$. This gave rise to a slightly cloudy water with a distinctive but not overpowering smell. No 
attempt was made to identify the species producing this putrefaction, but on separate occasions the method of growth gave a culture consistent in appearance and presumably in composition, although it appeared at times more potent than at others.

As is shown in Table $\mathrm{X}$ this type of culture produced a marked and sustained avoiding reaction in the Hemimysis used. On occasions, as in DHT I4, when the culture was especially strong, deaths might even be caused. The negative migration persisted when the culture was diluted first to $50 \%$ strength and then to $25 \%$; but when diluted to $10 \%$ no significant result was obtained. In an attempt to define more precisely the agent inducing this reaction a culture was passed through an ultra-filter, when a negative migration was still obtained. If a culture was aerated for $60 \mathrm{~min}$. before use, however, no significant result was obtained, although aeration for a shorter time did not seem adequate to remove the noxious agent, until a much more efficient diffuser and method of bubbling were adopted. The destruction or removal of the material inducing the avoidance by bubbling with air, left the possibility of its being oxidized or perhaps carried away in the stream of escaping bubbles. A culture was therefore bubbled with nitrogen and then tested in the apparatus (DHT 67), when no significant result was obtained. It may thus be concluded that the substance avoided is a volatile, watersoluble metabolic or decomposition product of the bacteria. In the light of this conclusion an attempt was made to remove the substance from a culture by bubbling and to reabsorb it in filtered water which could then be used in the apparatus. No significant movement in relation to such water was demonstrated.

With the above evidence that some of the migrations in relation to bacteria and phytoplankton were perhaps mediated by substances dissolved in the water, attempts were made to determine the reactions of Hemimysis to one or two simple substances.

The first of these tested was carbon dioxide. Sea water was saturated with carbon dioxide by bubbling with gas from a cylinder (and washed before use). When such saturated water was put into the apparatus and animals introduced, those going into the carbon-dioxide-rich side went immediately into convulsions and died within a matter of seconds without being able to escape to the other side of the apparatus. Those animals put into the other side made no attempt to move into the carbon-dioxide-rich water. When the saturated water was diluted down to Io \% with normal water and the animals introduced, then a rapid and sustained negative migration took place without any deaths. An equally clear reaction was got with a $5 \%$ dilution, but not with I and $\frac{1}{2} \%$, when no significant movement resulted. The $\mathrm{pH}$ of the $\frac{1}{2} \%$ dilution was about 8.0 , which is similar to that of the bacteria-rich water. The $\mathrm{pH}$ of the $5 \%$ dilution was about $7 \cdot 2$.

The second series tested migration in relation to degree of aeration. One 
sample of water was supersaturated by shaking vigorously, and another deaerated by subjecting to the reduced pressure of a powerful filter-pump together with shaking. When these two lots of treated water were put into opposite sides of the apparatus and animals introduced, then no significant departure from a uniform distribution was obtained. Similar results obtained with water deaerated by this means in one side and normal water in the other. If the water was deoxygenated by bubbling with washed nitrogen from a cylinder for $45 \mathrm{~min}$., then animals going into that side of the apparatus died within minutes but made no attempt to escape to the normal side. There were in this case no convulsions, and death was much slower than with

\section{Table XI. Hemimysis lamornaE and Miscellaneous SubStances}

Carbon-dioxide-rich water

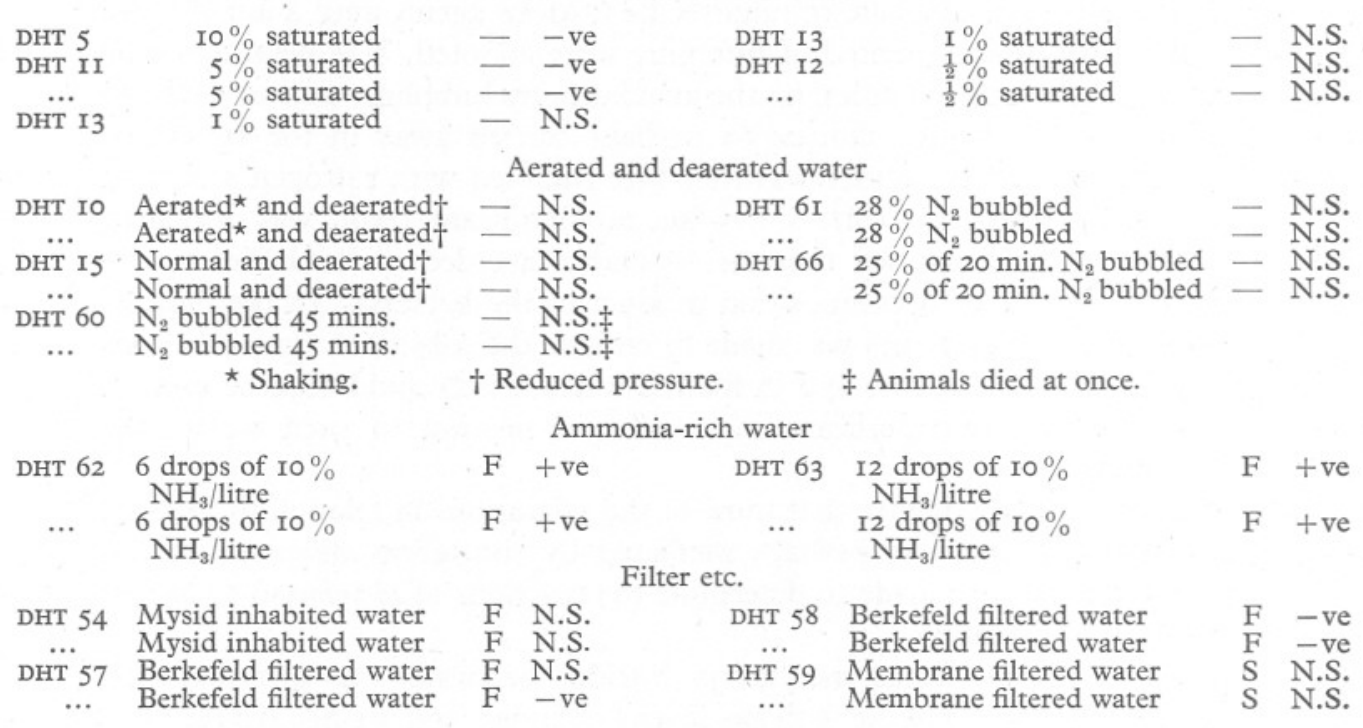

carbon dioxide. All movement ceased almost at once and the animals lay on their sides and gradually became opaque. If they were removed within about $5 \mathrm{~min}$. and put into well-aerated water, then a good proportion recovered completely. The nitrogen bubbled water was diluted down to $28 \%$; and water bubbled for $20 \mathrm{~min}$. was diluted down to $25 \%$ with normal water but no avoiding reaction towards either could be demonstrated, while no further deaths took place at these concentrations.

The possibility of ammonia being one of the bacterial decomposition products led to its being tested in the apparatus. 0.880 ammonia was diluted to $10 \%$ with sea water and six drops of this solution were added per litre of sea water, giving a $\mathrm{pH}$ of just over 8.8. This water was placed in one side of 
the apparatus and normal water in the other. The Hemimysis introduced moved immediately into the ammonia concentration and remained there. A precisely similar result was obtained using double the concentration of ammonia (I2 drops per litre).

Miscellaneous tests included one on water in which mysids had lived for some time. No significant migration in relation to this was obtained. The experiments referred to earlier as involving filtered water from various cultures, used water passed through a coarse Berkefeld plaster filter candle. The water was drawn through by suction with a siphon about $5 \mathrm{ft}$. long. The high proportion of negative results obtained with such water led to the filter itself being tested in the following manner. Previously ultra-filtered water (from the laboratory supply) was passed through the filter in the usual manner and put in one side of the apparatus, while unrefiltered water was put in the other. A marked negative migration in relation to such water was obtained on three occasions out of four. As a result of this test it was decided to disregard the experiments using water filtered in this way except for the first one involving bacteria water. It was advised that such plaster filters are liable to absorb substances from the water passed through them and later give them up to other water. It seems probable that something was absorbed from the bacteria culture and released afterwards to contaminate the various types of water passed through it. The pores of the filter would also hold organic matter of various kinds from the diatoms, etc., and this could decompose and then contaminate other water. Water filtered through a membrane filter was tested and found to induce no significant migration. It did not prove practicable, however, to use this method for filtering cultures, as it was extremely slow. It was finally decided to use the centrifuging method already referred to in order to remove cells and leave the culture otherwise unaffected.

Besides the above experiments involving cultures and chemical substances, fourteen control experiments were performed with the apparatus uniformly filled with water of some kind. None of these resulted in a whole experiment being termed significant but occasionally, as already mentioned in DHT 30 and in HCT 4, a temporary distribution differing significantly from a uniform one was obtained. The frequency with which each particular reading occurred in the nine experiments done in the straight horizontal apparatus is shown in Text-fig. 2A. The form of the curve drawn through the points is typically that which would be expected were the distribution of the animals in the tube random. Such significant departures from a uniform distribution as do occur in the control experiments could perhaps be a manifestation of the shoaling habit which is common in these animals, but this tendency is not marked enough to appear in the figure. The second curve (Text-fig. $2 \mathrm{~B}$ ) shows the frequency with which each particular reading occurred in three control experiments done in the circular horizontal tube. This includes all the 
readings for each of the six sectors, and is asymmetrical because the one or two high readings (to be expected by chance) each necessarily result in there being several low readings, since the remaining few animals have to be distributed amongst the other five sectors.

It may therefore be concluded from the control experiments that in the uniform tubes there is no tendency to aggregate in any particular section, and those significant departures from an even distribution which are found in the remainder of the experiments are due to the environmental conditions in the tubes.

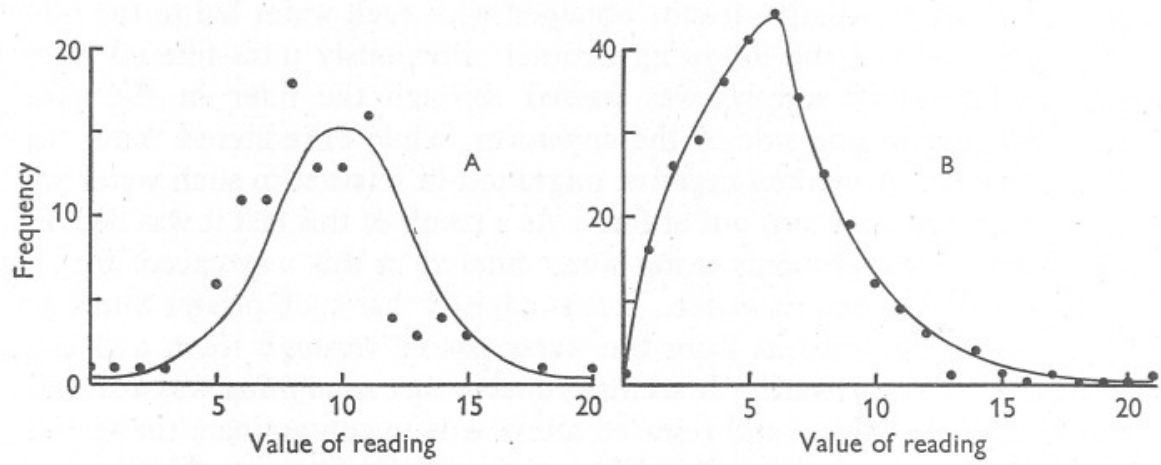

Text-fig. 2. Summary of control experiments with Hemimysis lamornae. A, frequency of occurrence of readings in Exps. DHT I, 30, 38, 39 and 40. B, the same in Exps. HCT 2, 4 and 17 .

\section{Other mysids}

Experiments were performed with four other species of mysid-Praunus neglectus, P. flexuosus, Neomysis integer and Mesopodopsis slabberi. The behaviour of these species appearing to be similar, and rather few experiments having been done with each, it seems most convenient to consider all the results together.

\section{Experiments involving Diatoms}

As seen from the summary distribution of results (Table XII), out of twenty-four experiments involving various diatoms twenty gave significant positive migrations and four gave no significant result. Movement was most marked into Nitzschia closterium (the minute Plymouth strain) and Thalassiosira gravida; while neither of two experiments performed with Eucampia zoodiacus gave a significant result. One of the experiments with Neomysis integer was performed in the dark and gave no significant migration until the apparatus was moved into the light. The distribution then became positive. In one of the experiments with Neomysis the diatom culture was deoxygenated before use by subjecting it to reduced pressure combined with shaking and in another the diatoms were killed by heating to $80^{\circ} \mathrm{C}$., washed on a filter and 


\section{Table XII. Other Mysids and Phytoplankton, etc.}

(I) Praunus neglectus

\begin{tabular}{|c|c|c|c|c|c|c|c|}
\hline \multicolumn{4}{|c|}{ Nitzschia closterium } & \multicolumn{4}{|c|}{ Flagellate I2 } \\
\hline НСТ 60 & 3000 & F & $+\mathrm{ve}$ & нст 38 & 8 & $\mathrm{~F}$ & N.S \\
\hline HCT 65 & 440 & $\mathrm{~F}$ & +ve & HCT $4 \mathrm{I}$ & II & $\mathrm{S}$ & \\
\hline HCT 63 & 2300 & $\mathrm{~S}$ & $+\mathrm{ve}^{\star}$ & & & & \\
\hline \multicolumn{4}{|c|}{ Thalassiosira gravida } & \multicolumn{4}{|c|}{ Flagellate $\mathrm{L}_{4}(\mathrm{I} 3 / 4) 2 \mathrm{~L}$ Clone 6} \\
\hline DHT 32 & II5 & $\mathrm{F}$ & + ve & HCT 44 & 650 & $\mathrm{~F}$ & N.S. \\
\hline$\cdots$ & II5 & $\mathrm{F}$ & $+\mathrm{ve}$ & HCT 45 & 505 & S & $+\mathrm{ve}$ \\
\hline \multicolumn{4}{|c|}{ Chlorella stigmatophora } & \multicolumn{4}{|c|}{ Exuviaella baltica } \\
\hline HCT $6 \mathrm{I}$ & $\begin{array}{l}1210 \\
1840\end{array}$ & $\stackrel{\mathrm{F}}{\mathrm{S}}$ & $\begin{array}{l}\text { N.s. } \\
\text { + ve† }\end{array}$ & HCT 42 & 5 & F & N.S. \\
\hline \multicolumn{4}{|c|}{ Eucampia zoodiacus } & DHT 2 I & $3 I$ & S & $+\mathrm{ve}$ \\
\hline HCT 69 & $I_{2}^{\frac{1}{2}}$ & F & N.S. & \multicolumn{4}{|c|}{ Zooplankton } \\
\hline \multicolumn{4}{|c|}{$\begin{array}{l}\text { Oxyrrhis marina, Rhodomonas sp. and } \\
\text { Nitzschia closterium }\end{array}$} & $\begin{array}{l}\text { HCT } 36 \\
\text { HCT } 28\end{array}$ & 二 & $\stackrel{\mathrm{F}}{\mathrm{S}}$ & $\begin{array}{l}\text { N.S. } \\
\text { N.S. }\end{array}$ \\
\hline HCT 32 & II & $\mathrm{F}$ & $+\mathrm{ve}$ & HCT 39 & - & $\mathrm{s}$ & N.S. \\
\hline HCT 34 & 7 & $\mathrm{~F}$ & N. & \multirow{2}{*}{\multicolumn{4}{|c|}{ Bacteria }} \\
\hline HCT 62 & 34 & $\mathrm{~S}$ & 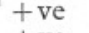 & & & & \\
\hline HCT 64 & I7 & $\mathrm{S}$ & $+\mathrm{ve}$ & HCT 59 & - & $\mathrm{F}$ & - vef \\
\hline \multicolumn{4}{|c|}{ Chlamydomonas sp. } & \multicolumn{4}{|c|}{ Ammonia } \\
\hline $\begin{array}{l}\text { HCT } 27 \\
\text { HCT } 68\end{array}$ & $\begin{array}{l}275 \\
200\end{array}$ & S & $+\mathrm{ve}^{\star}$ & HCT 73 & - & $\mathrm{s}$ & N.S. \\
\hline & & & . & 141 & & & \\
\hline
\end{tabular}

(2) Praunus flexuosus

Eucampia zoodiacus

$\begin{array}{ccc}\text { HCT II } & \text { I.4 S } & \text { S } \\ & \text { Chlamydomonas sp. } \\ \text { P 66 } & \text { 8ro } \quad \text { F } \\ & \text { Zooplankton } \\ \text { HCT 9 } & -\quad \text { S }\end{array}$

N.S.

N.S,

- ve HCT I2

\section{Thalassiosira gravida}

$\begin{array}{llll}\text { HCT I3 } & \text { I20 } & \text { S } & + \text { ve } \\ \text { HCT I4 } & \text { I00 } & \text { S } & \text { N.S. }\end{array}$

Bacteria

- F -ve

(3) Neomysis integer

Nitzschia closterium

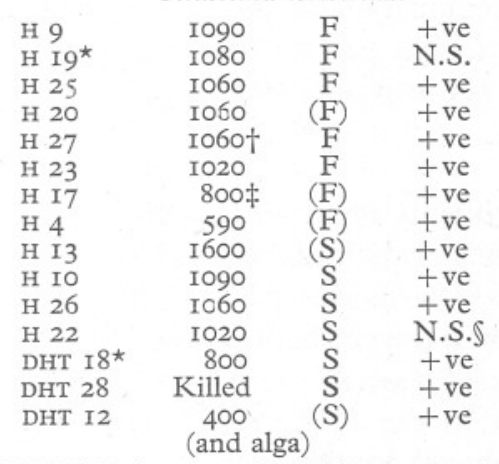

* Half $N$. integer and half Mesopodopsis slabberi.

$\ddagger$ Cells resuspended.
Non-motile green alga

$\begin{array}{lrrr}\text { H I } 4 & \text { I } 400 & \text { S } & \text { +ve } \\ \text { H } 6 & 50 & \text { (F) } & \text { N.S. }\end{array}$

\section{Miscellaneous}

H 24 I060 Nitzschia and tinted F N.S.

H 5830 Nitzschia and tinted (F) N.S.

H 7830 Nitzschia and tinted S +ve

H 8 Filtered Nitzschia (S) N.S.

H 2 I Filtered Nitzschia (F) N.S.

$\begin{array}{ll}\text { H } 29 \text { Kieselguhr } & \text { (S) N.S. }\end{array}$

$\mathrm{H}$ II Tinted water (S) N.S.

N.B. When the letters $\mathrm{F}$ and $\mathrm{S}$ are bracketed in this table the probable state of the animals is indicated.

† Culture deoxygenated.

$\S+$ ve in light (performed largely in dark). 


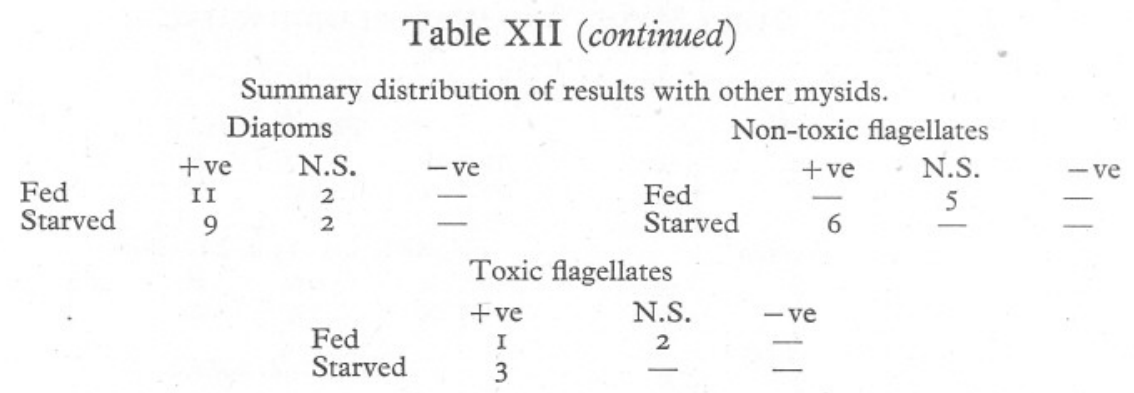

resuspended in filtered water before use. In both these experiments marked positive migrations were still obtained. This whole series is distinctive for the high proportion of positive results, there being no negative ones and no apparent difference in behaviour between fed and starved animals.

\section{Experiments involving Flagellates}

Of eleven experiments with typically 'non-toxic' flagellates five results, all with fed animals, were not significant and six, all with starved animals, were significantly positive. These include two experiments with Chlorella stigmatophora rather below its optimum concentration, and two with an unidentified non-motile green alga which was probably a Chlorella. Of two experiments with Exuviaella baltica, which had induced no positive migration in Hemimysis lamornae, one significant positive result was obtained, this being with starved animals and a much higher concentration of cells than used previously. The other positive results were with Chlamydomonas and the flagellate $\mathrm{L}_{4}(\mathrm{r} 3 / 4)$ 2 L Clone 6. Again there were no negative results.

Finally, of four experiments with the mixed Oxyrrhis culture and two with Flagellate I2, both in the 'toxic' group, four positive results were obtained, the two not significant ones being with fed animals. The Flagellate I2 concentrations used were lower than those used previously, and the proportions of Rhodomonas to Oxyrrhis were generally low so this perhaps may account for the absence of negative migrations amongst these experiments.

\section{Miscellaneous Experiments}

Amongst the various miscellaneous experiments reported in Table XII is the one involving Praunus flexuosus and a concentration of zooplankton which led to the series using bacteria. In this there was no evidence of any movement into the sector rich in zooplankton taken from a townet haul nor was there in three other similar experiments with $P$. neglectus, all of which gave not significant results. The negative movement in the P. flexuosus experiment must almost certainly be taken as being induced by the growth of bacteria which took place in the tube. This growth, although making the water 
slightly cloudy, was not sufficient to kill any of the animals used. Two experiments with independently produced bacteria cultures confirmed the negative migration.

An experiment with the non-motile alga culture in one side and Nitzschia in the other showed a clear migration into the latter, despite the not unattractive nature of the alga as shown in an independent experiment. One involving a suspension of Kieselguhr (diatomaceous earth) and also six control experiments using various animals all gave no significant results, as did three with water tinted with water colours to resemble a diatom culture.

\section{Table XIII. ARtemia SALINA and Diatoms and Flagellates}

\begin{tabular}{|c|c|c|c|c|c|c|c|}
\hline \multicolumn{4}{|c|}{ Nitzschia closterium } & \multicolumn{4}{|c|}{ Hemiselmis rufescens } \\
\hline P 42 & 3720 & F & N.S.* * & 2P I9 & 3500 & S & N.S. \\
\hline $2 \mathrm{P} 15$ & 2380 & F & & $2 \mathrm{P} \mathrm{I8}$ & 2820 & $\mathrm{~S}$ & \\
\hline $2 \mathrm{PI}_{4}$ & 2340 & F & N.S.t & & & & \\
\hline 2P I6 & 1800 & F & N.S. $\ddagger$ & & & & \\
\hline DHT 44 & $\begin{array}{l}480 \\
480\end{array}$ & $\begin{array}{l}\mathrm{F} \\
\mathrm{F}\end{array}$ & $\begin{array}{l}\text { N.S.S } \\
+\mathrm{ve}\end{array}$ & \multicolumn{4}{|c|}{ Flagellate 4} \\
\hline DHT 43 & $\begin{array}{r}400 \\
43\end{array}$ & F & N.S. & HCT 7 & 72 & S & \\
\hline & 43 & F & $+\mathrm{ve}$ & HCT 8 & 70 & S & N.S. \\
\hline $2 \mathrm{P} \mathrm{I}_{7}$ & 1005 & S & N.S. & & & & \\
\hline P 43 & 820 & S & N.S. $\|$ & \multirow{2}{*}{\multicolumn{3}{|c|}{$\begin{array}{l}\text { F }- \text { ve } 2 \text { nd day. } \\
\$ 2 \text { rds + ve. } \\
\text { II } 3 \text { rds + ve. }\end{array}$}} & \\
\hline \multicolumn{4}{|c|}{$\begin{array}{l}\star \\
\dagger \\
\dagger \text { Poor gradient. }\end{array}$} & & & & \\
\hline
\end{tabular}

Summary distribution of results with Artemia salina and diatoms and flagellates.

$\begin{array}{lccc} & +\mathrm{ve} & \text { N.S. } & -\mathrm{ve} \\ \text { Fed } & 2 & 6 & - \\ \text { Starved } & \text { I } & 5 & -\end{array}$

\section{Artemia salina}

Fifteen experiments were performed using specimens of Artemia salina, the brine shrimp, which had been reared in captivity at Plymouth. Of ten of these involving Nitzschia closterium, two gave significant positive results (both with fed animals) and two had positive tendencies; the remainder, with the exception of two with negative tendencies on the second day, being not significant (Table XIII). Of two experiments with Hemiselmis rufescens, one was significantly positive and of two with Flagellate 4 both were not significant. Most of the results were thus not significant but again there were no negative results.

\section{Decapod larvae}

Twelve experiments with decapod larvae gave much more variable results. Of nine with cultures not considered toxic two positive and two negative results were obtained; and of three with the mixed Oxyrrhis culture, one positive, one negative and one not significant. These experiments were done with various kinds of zoea and megalopa larvae, but there did not appear to 
be any correlation between the species used and the type of result obtained. There may perhaps not be enough experiments in the series for the usual trends to become apparent, but it seems more likely that a rather different type of behaviour is being encountered.

\section{Table XIV. Decapod larvae and Diatoms and Flagellates}

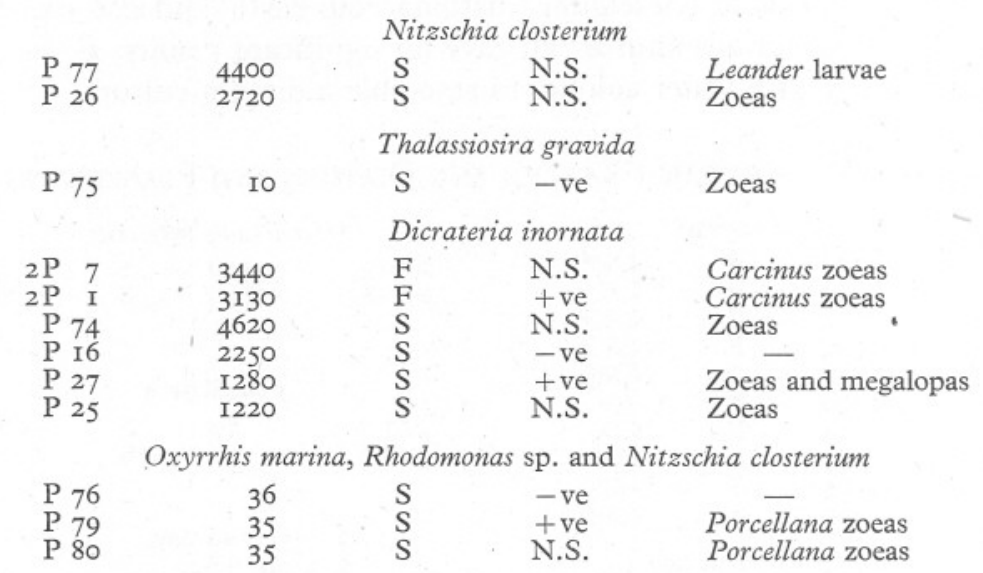

Summary distribution of results with Decapod larvae and all diatoms and flagellates

$\begin{array}{lccc} & \text { +ve } & \text { N.S. } & - \text { ve } \\ \text { Fed } & \text { I } & \text { I } & - \\ \text { Starved } & 2 & 5 & 3\end{array}$

Small copepods, etc.

The six experiments performed with small copepods of various kinds all gave significant positive migrations, one being with fed animals (Table XV). The three diatoms used in this series have all on other occasions seemed acceptable to animals, and the high incidence of positive results may perhaps depend upon this and the fact that many more animals than usual were used in each experiment so that a proportionally small movement into one side could more easily be designated significant.

Two other experiments, one with Sagitta sp. and the other with small medusae, are, for the sake of convenience, included in this table. No significant migration was apparent in either of them.

\section{Calanus finmarchicus}

Forty-seven experiments were performed with Calanus finmarchicus and various diatoms and flagellates. These, as Table XVI shows, gave very variable results. The twenty-eight with diatoms gave four positive results (all with starved animals) and three negative (one with fed and two with starved animals) and the eleven with non-toxic flagellates three positive 
results (two with fed and one with starved animals); the remainder being not significant. This gives a total distribution of seven positive to twenty-nine not significant to three negative.

The results with toxic flagellates were perhaps more consistent-two negative and six not significant out of a total of eight; but considering the series with Calanus as a whole it would seem unwise to place any reliance upon them. Ten control experiments and one each with bacteria, oxygen and carbon dioxide all gave not significant results.

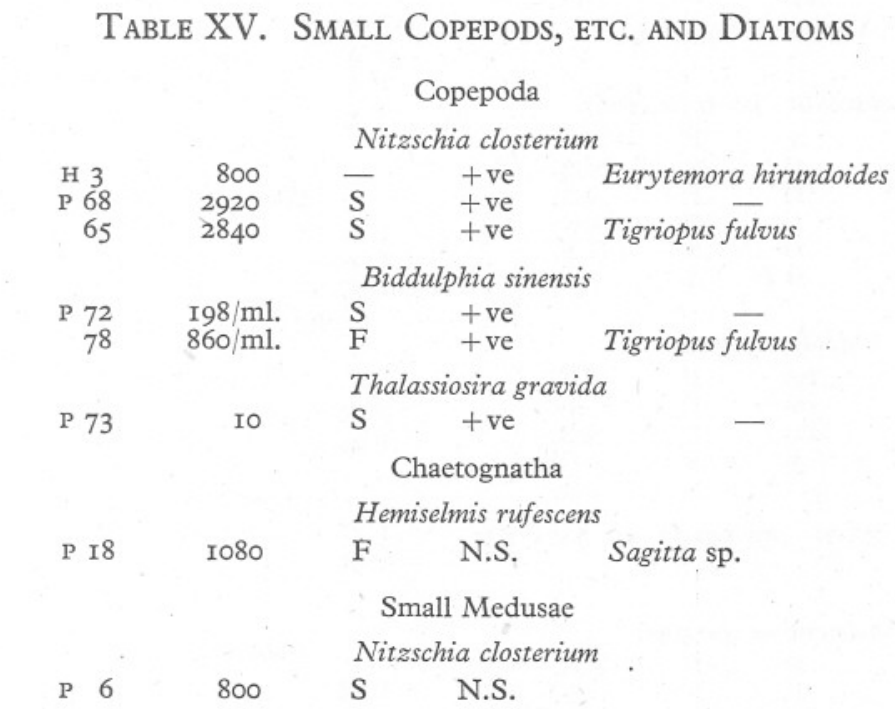

Summary distribution of results with small copepods and diatoms

$\begin{array}{lccc} & + \text { ve } & \text { N.S. } & - \text { ve } \\ \text { Fed } & \text { I } & - & -\end{array}$

The most reasonable deduction to be made is that Calanus shows no significant migration in relation to the various phytoplankton organisms used, and that such departures from an even distribution as occur are the result of some swarming or shoaling behaviour and are independent of the distribution of phytoplankton in the tube.

\section{The Vertical Apparatus}

Most of the experiments using the vertical apparatus were done with the copepod Calanus finmarchicus. The first ten were performed in the open tank with the apparatus in its original form and these are considered first.

In each experiment the water in one of the tubes had previously been drawn, by siphoning, through a Berkefeld-plaster filter-candle; and the water in the other tube, after similar filtration, had been enriched with one 


\section{Table XVI. Calanus finmarchicus and Diatoms and Flagellates}

Nitzschia closterium

$\begin{array}{lrll}\text { P 5I } & 3440 & \text { F } & \text { N.S.* } \\ \text { P I2 } & 3060 & \text { F } & \text { N.S. } \\ \text { P 23 } & \text { I900 } & \text { F } & \text { N.S.* } \\ \text { P 5 } & 500 & \text { F } & \text { N.S. } \\ \text { P I } & 970 & \text { S } & \text { +ve } \\ \text { P 2 } & 970 & \text { S } & \text { N.S. } \\ \text { P 3 } & 970 & \text { S } & \text { N.S. } \\ \text { P 7 } & 490 & \text { S } & \text { +ve } \\ \text { P } 8 & 490 & \text { S } & \text { N.S. } \\ & \text { * Medium Nitzschia. }\end{array}$

Thalassiosira nordenskiöldii

$\begin{array}{llll}\text { P } 58 & 20 & \text { F } & \text { N.S. } \\ \text { P } 53 & \text { I8 } & \text { F } & \text { N.S. } \\ \text { P } 54 & \text { I8 } & \text { F } & \text { N.S. } \\ \text { M } 3 & \text { I3 } & \text { S } & - \text { ve } \\ \text { M } 4 & \text { I2 } & \text { S } & \text { N.S. } \\ \text { P } 67 & \text { IO } \frac{1}{2} & \text { S } & + \text { ve }\end{array}$

Biddulphia sinensis

$\begin{array}{llll}\text { P } 57 & 222 & \text { F } & \text { N.S. } \\ \text { P } 55 & \text { I } 86 & \text { F } & \text {-ve } \\ \text { P } 56 & 223 & \text { S } & \text { N.S. } \\ \text { P } 52 & 39 & \text { S } & \text { N.S. } \\ \text { P } 70 & \text { - } & \text { S } & \text { +ve }\end{array}$

* Culture used previously as food for H. lamornae.

\begin{tabular}{lccc}
\multicolumn{4}{c}{ Skeletonema costatum } \\
P I0 & 23 & F & N.S. \\
P 9 & 23 & S & N.S. \\
P II & 23 & S & - ve \\
P I5 & Filtered & S & N.S.
\end{tabular}

Coscinodiscus concinnus
Oxyrrhis marina, Rhodomonas $\mathrm{sp}$. and Nitzschia closterium

\begin{tabular}{|c|c|c|c|}
\hline P 32 & 22 & $\mathrm{~F}$ & N.S. \\
\hline P 35 & 9 & $\mathrm{~F}$ & N.S. \\
\hline P 28 & 4 & $\mathrm{~F}$ & N.S. \\
\hline P 34 & Filtered & $\mathrm{F}$ & - ve \\
\hline P 3 I & 22 & $\mathrm{~S}$ & N.S. \\
\hline $2 \mathrm{P} I 3$ & 3 & S & -ve \\
\hline \multicolumn{3}{|c|}{ Dicrateria inornata } & \\
\hline $2 \times 8$ & 3220 & $\mathrm{~F}$ & N.S. \\
\hline P 22 & 2060 & F & +ve \\
\hline P 4 & 3900 & $\mathrm{~S}$ & N.S.* \\
\hline P I7 & 850 & $\mathrm{~S}$ & N.S. \\
\hline
\end{tabular}

Phaeocystis pouchetii

$\begin{array}{llll}\text { P } 50 & -\star & \text { F } & \text { N.S. } \\ \text { P } 40 & 5 \text { I } & \text { S } & \text { +ve } \\ \text { P } 37 & 35 & \text { S } & \text { N.S. }\end{array}$

* Old disintegrating culture.

\begin{tabular}{lcrl}
\multicolumn{4}{c}{ Cryptomonad } \\
P 46 & Iro & S & N.S. \\
P 47 & Iro & S & N.S. \\
& & Gymnodinium & sp. \\
P 48 & r 20 & F & N.S. * \\
P 39 & 75 & F & N.S. \\
& $\star 3$ rds +ve. &
\end{tabular}

P I4 $\begin{array}{ccc}\text { Hemiselmis rufescens } \\ \text { II68 }\end{array}$

Nitzschia sp. and a flagellate

$\begin{array}{lccc}\text { P 7I } & \text { 286 } & \text { F } & \text { N.S. } \\ & \text { Bacteria } & & \\ \text { P 24 } & - & \text { F } & \text { N.S. } \\ & \text { Oxygen } & & \\ \text { P 44 } & - & \text { F } & \text { N.S. } \\ & \text { Carbon dioxide } & \\ \text { P 4I } & - & \text { S } & \text { N.S. }\end{array}$

Summary_distribution of results with C. finmarchicus

Diatoms

$\begin{array}{lccc} & \text { +ve } & \text { N.S. } & \text {-ve } \\ \text { Fed } & - & \text { I3 } & \text { I } \\ \text { Starved } & 4 & 8 & 2\end{array}$
Non-toxic flagellates

$\begin{array}{lccc} & + \text { ve } & \text { N.S. } & - \text { ve } \\ \text { Fed } & 2 & 3 & - \\ \text { Starved } & \text { I } & 5 & -\end{array}$

Toxic flagellates

$\begin{array}{lccc} & \text { +ve } & \text { N.S. } & \text {-ve } \\ \text { Fed } & - & 5 & \text { I } \\ \text { Starved } & - & \text { I } & \text { I }\end{array}$


of a variety of phytoplankton cultures. Twice, exactly Ioo animals were picked out and counted before use, but otherwise only roughly equal numbers were put in and then accurately counted after the experiment. The number of Calanus swimming in the top compartment of each tube was counted at various irregularly spaced times during the day and night; each experiment lasting about $24 \mathrm{hr}$. Because of this irregularity it was decided to assess the results on, and apply the test of significance to, the mean of all the readings in each experiment. The percentages calculated from the mean number of animals swimming up in each experiment are given in Table XVII. It will be seen that these figures are small and variable, but that, in all experiments

\section{Table XVII. Results of First Ten Experiments out-of-DOORS With CALANUS FINMARCHICUS IN THE VERTICAL APPARATUS}

\begin{tabular}{|c|c|c|c|c|c|}
\hline \multirow{2}{*}{$\begin{array}{l}\text { Serial } \\
\text { no. }\end{array}$} & \multirow[b]{2}{*}{ Phytoplankton organism } & \multicolumn{2}{|c|}{ No. of animals } & \multicolumn{2}{|c|}{$\begin{array}{l}\text { Total mean \% } \\
\text { swimming up }\end{array}$} \\
\hline & & Contl. & Exptl. & Contl. & Exptl. \\
\hline ML I6 & Mixed diatoms & 58 & 60 & 0.2 & $\mathrm{I} \cdot 5$ \\
\hline ML 17 & Mixed diatoms and flagellates & 217 & 226 & $4 \cdot 0$ & 3.9 \\
\hline ML 23 & Mixed diatoms and flagellates & 55 & 59 & $i \cdot 3$ & $3 \cdot 8$ \\
\hline ML 25 & Syracosphaera carterae & 73 & 82 & 0.3 & 3.6 \\
\hline ML 29 & Ditylum brightwellii & 100 & 100 & 0.8 & $4 \cdot 4$ \\
\hline ML 30 & Gymnodinium sp. & 99 & II9 & $I \cdot 2$ & $5 \cdot 5$ \\
\hline ML 33 & Water rich in Mesodinium ${ }^{\star}$ & 100 & 100 & 0.9 & $\mathrm{I} \cdot 9$ \\
\hline ML 34 & Peridinium trochoidium & 84 & 97 & $I \cdot O$ & $2 \cdot 8$ \\
\hline ML 36 & $\begin{array}{l}\text { P. trochoidium and Gymno- } \\
\text { dinium sp. }\end{array}$ & 142 & 218 & $2 \cdot 8$ & $2 \cdot 7$ \\
\hline ML 37 & $\begin{array}{l}P \text {. trochoidium and Gymno- } \\
\text { dinium sp. }\end{array}$ & 215 & 270 & 0.5 & $I \cdot 2$ \\
\hline
\end{tabular}

A summary of the $\chi^{2}$ results confirming that these differences are significant is as follows:

$\begin{array}{lccc} & \begin{array}{c}\text { Degrees of } \\ \text { freedom }\end{array} & \chi^{2} & P \\ \text { Interaction } & 9 & 4.98 & 0.85 \\ \text { Pooled readings } & \text { I } & 5.0 & \mathrm{ca} .0 .03 \\ \text { Total of individuals readings } & \text { Io } & 9.98 & \end{array}$

* This water was unfiltered and as taken from the sea during a rich outburst of the ciliate Mesodinium sp.

but two, there are more animals swimming up in the enriched water than in the filtered water. If the test of independence described earlier is applied to each experiment, in none is the difference greater than might be expected by chance, but if it is applied to the pooled results, then the difference in behaviour between the two sets of tubes is clearly seen to be significant at the $5 \%$ level $(P=0.03)$. The test for homogeneity confirms that this pooled result is reliable $(P=0.85)$ and is in fact made up of a series of small and almost uniform differences all in the same direction.

As the reaction of the animals to all these different phytoplankton organisms 
appears to be similar, it may be taken as permissible to calculate a total mean percentage of animals swimming up for the whole series of experiments. If this is done, $\mathrm{I} \cdot 3 \%$ are found to swim up in the filtered water and $3.1 \%$ in the enriched.

After these preliminary experiments I03 were performed with the apparatus indoors in the aquarium tank. This whole series is more uniform in that readings were taken at regular intervals after the start of the experiment, and the same number of counted animals was used each time. The fact that each experiment involved two control and two experimental tubes gave a further check on the reliability of the results. The whole series falls into ten groups dependent upon the phytoplankton organisms used and may best be considered in this manner. Detail of the method of presentation of the results is given in the first group.

\section{Group I: Skeletonema costatum}

Ten experiments were performed with the pair of control tubes containing water filtered by suction through a Whatman no. I filter-paper and aerated before use by shaking, and with the experimental tubes containing similar water enriched with a culture of $S$. costatum. A small quantity of tap water was added to the water in the control tubes to make its specific gravity equal to that of the enriched water, the latter being slightly more dilute owing to the addition of the culture. The volume added was calculated, and was of the order of 5-10 $\mathrm{ml}$. depending upon the amount of culture used. Twenty Calanus finmarchicus were picked out from a townet catch taken as short a time as possible before the experiment, and put into the top of each tube. The tubes were then suspended in the tank and the number of animals in the top compartment of each was counted from time to time. In order to economize in the use of cultures it was sometimes decided, especially when an experiment was of short duration, to use the water more than once. On these occasions it was poured out, filtered through coarse silk to remove the animals, and replaced in the tubes ready for use with a fresh sample of Calanus.

A satisfactory way of showing pictorially whether there was any difference in behaviour between the pairs of tubes was found to be as follows. The frequency with which each particular reading occurs throughout the whole group of experiments is determined, and this number plotted against the value of the reading. The result for all the experiments involving Skeletonema costatum is shown in Text-fig. 3(I). The ten experiments gave a total of seventy-three readings, each in pairs (there being two control and two experimental tubes), and this provides I46 values for filtered water and I46 for enriched. It can be seen at once that there are more of the higher readings in the enriched water and in fact the curve for the latter bears a close resemblance to that for filtered water but is moved bodily to the right. 

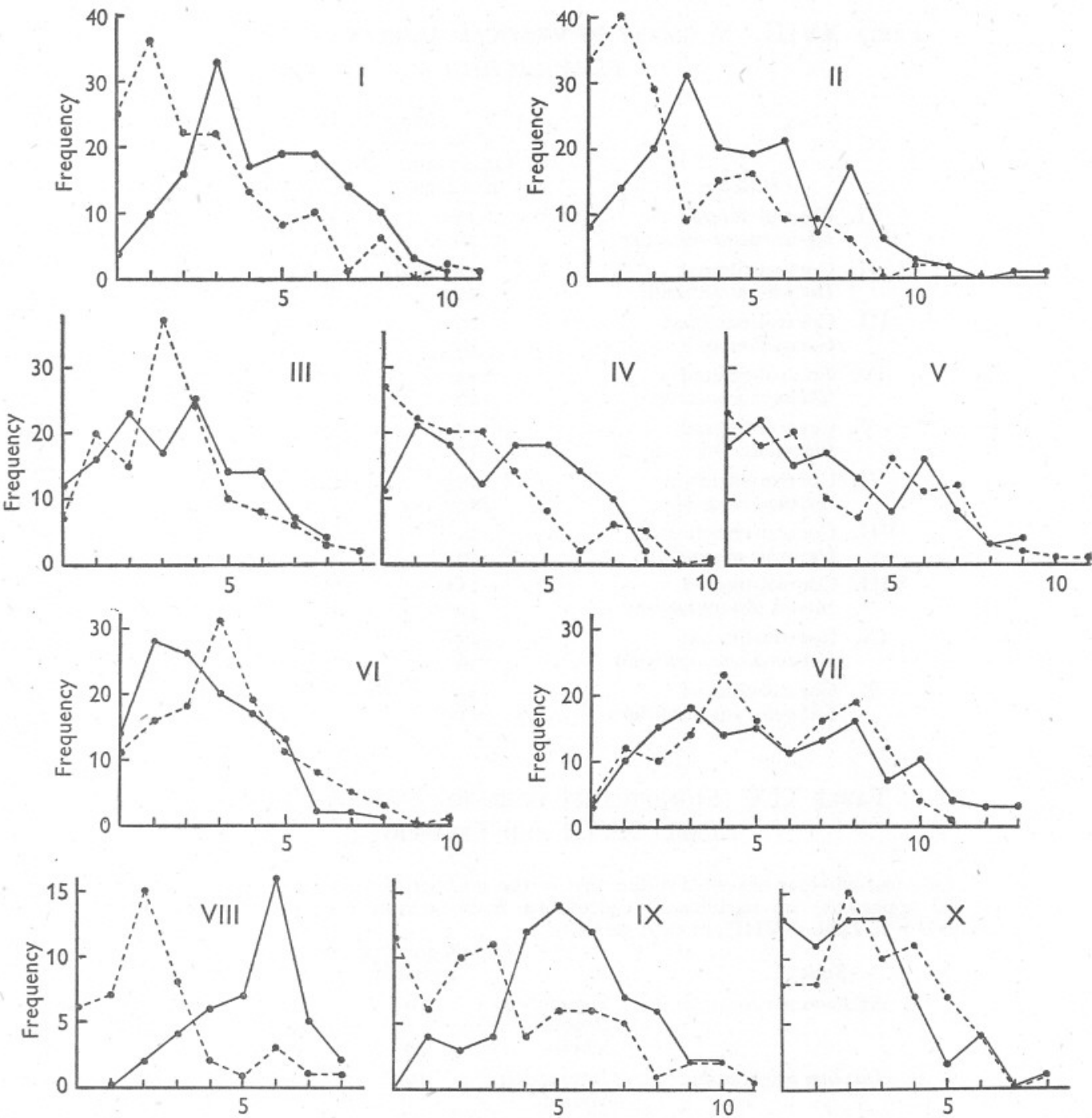

Number swimming up, out of 20

Text-fig. 3. Upward movement of Calanus in water containing various organisms, each graph representing the results of a series of comparable experiments with the organism stated. Each graph plots the frequencies of the different values, out of twenty, for the number of animals moving up-either in water rich in the experimental culture (continuous line), or in a control medium (broken line). The control was usually filtered sea water, but enriched water was chosen for series III, VI and VII. I, Skeletonema costatum; II, Ditylum brightwellii; III, Gymnodinium I; IV, Chlamydomonas sp.; V, Flagellate One; VI, Gymnodinium II; VII, Oxyrrhis, Rhodomonas, and Nitzschia; VIII, mixed phytoplankton; IX, Coscinodiscus concinnus; X, Chlorella stigmatophora. See Tables XVIII and XIX. 
Table XVIII. Summary of Vertical Results with Calanus FINMARCHICUS

\begin{tabular}{r}
\multicolumn{1}{c}{ Series } \\
I. Control-filtered \\
Skeletonema costatum \\
II. Control-filtered \\
Ditylum brightwellii \\
III. Control-enriched \\
Gymnodinium I \\
IV. Control-filtered \\
$\quad$ Chlamydomonas sp. \\
V. Control-filtered \\
Flagellate One \\
VI. Control-enriched \\
Gymnodinium II \\
VII. Control-enriched \\
Oxyrrhis marina etc. \\
VIII. Control-filtered \\
Mixed phytoplankton \\
IX. Control-filtered \\
Coscinodiscus concinnus \\
X. Control-filtered \\
Chlorella stigmatophora
\end{tabular}

$\begin{array}{ccc}\begin{array}{c}\text { On } 60 \text { min. } \\ \text { readings }\end{array} & \begin{array}{c}\text { On Ist four } \\ \text { readings }\end{array} & \begin{array}{c}\text { On all } \\ \text { readings }\end{array} \\ 27.0 & \text { I6.4 } & \text { I0.5 } \\ 27.8 & 23.9 & \text { I7.5 } \\ 21.7 & 22.4 & \text { I4.0 } \\ 29.5 & 29.2 & 22.5 \\ 20.0 & \text { I8.8 } & \text { I6.6 } \\ 20.2 & \text { I8.9 } & \text { I7.4 } \\ \text { I4.4 } & \text { I4.8 } & \text { I2.9 } \\ 20.2 & \text { I9.3 } & \text { I6.9 } \\ \text { I7.5 } & \text { I8.2 } & \text { I6.5 } \\ \text { I7.2 } & \text { I8.1 } & \text { I6.3 } \\ \text { I5.9 } & \text { I4.2 } & \text { I6.4 } \\ \text { I3.6 } & \text { II.5 } & \text { I2.5 } \\ 29.7 & 27.9 & 25.5 \\ 30.7 & 29.1 & 27.9 \\ \text { I5.0 } & \text { I5.0 } & \text { I2.2 } \\ 30.8 & 29.6 & 26.6 \\ 23.0 & 20.8 & 22.2 \\ 36.0 & 29.1 & 26.3 \\ \text { I5.5 } & \text { I4.8 } & \text { I4.0 } \\ 11.5 & 13.1 & \text { I1.4 } \\ & & \end{array}$

\section{Table XIX. Significance tests for Data Presented in TABle XVIII AND TeXT-FIG. 3}

(These test whether observed differences in the number of Calanus swimming up (in the vertical apparatus) are significant. Calculation from $60 \mathrm{~min}$. reading for all experiments (column $\mathrm{I}$ in Table XVIII), in each series.)

\section{Series}

I. Skeletonema costatum

II. Ditylum brightwellii

IV. Chlamydomonas sp.

VI. Gymnodinium II

VIII. Mixed phytoplankton

IX. Coscinodiscus concinnus

X. Chlorella stigmatophora

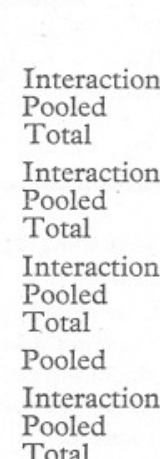

Total

Interaction Total

Pooled

\section{Degrees of freedom}

19
1
20
19
1
20
23
1
24
1
5
1
6
9
1
10

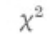

$22 \cdot 10$

I6. 19

$38 \cdot 29$

I5.88

$6 \cdot 73$

$22 \cdot 6 \mathrm{I}$

$3 \mathrm{I} \cdot 97$

5.65

$37 \cdot 62$

0.95

I.69

8.51

$10 \cdot 20$

13.65

$8 \cdot 12$

$2 \mathrm{I} \cdot 77$

I. 37

$$
\begin{gathered}
P \\
c a .0 .25 \\
<0.001 \\
0.7 \\
0.01 \\
>0.10 \\
<0.02 \\
\text { ca. } 0.35 \\
\text { ca. } 0.9 \\
<\mathbf{0 . 0 1} \\
0.15 \\
<\mathbf{0 . 0 1} \\
\text { ca. } 0.25
\end{gathered}
$$


To test whether the difference is significant, the test of independence can be applied either to one reading from each particular experiment or to the mean of a group or the mean of all the readings from each particular experiment. Examination of the results for one or two of the experiments revealed that the number of animals swimming up generally rose to a maximum at about I-I $\frac{1}{2} \mathrm{hr}$. and then fell gradually for the rest of the time. It was decided consequently to apply the test to the reading taken at, or as close as possible to, I hr. after the start of the experiment and to use only this one reading from each experiment. When this is done for the Skeletonema results it is found that only four out of the total of twenty show significant differences. (The test is applied twice to each reading; each time one control tube being compared with one experimental tube, and this results in twenty values of $\chi^{2}$ for the ten experiments.) When, however, the single readings are lumped together and the test applied to this pooled result the whole series is shown clearly to be significant and, further, satisfies the test for homogeneity. A summary of the values of $\chi^{2}$ concerned is given in Table XIX.

It may therefore be concluded that a significantly greater number of Calanus swim up in the enriched tubes than in the filtered tubes. The total mean percentage swimming up, as calculated from the 60 min. readings, may be taken as a measure of the actual difference between the two tubes. This is I $6.0 \%$ for the filtered water and $27.8 \%$ for the enriched. The average of the concentrations of cells in the enriched water used in the various experiments is $\mathrm{I} 8.3$ cells of Skeletonema costatum per $\mathrm{mm} .^{3}$. This figure includes both single cells and cells in chains of various numbers.

\section{Group II. Ditylum brightwellii}

A series of experiments precisely similar to the above but using the diatom Ditylum brightwellii gave similar results. The graph in Text-fig. 3 (II) reveals a similar displacement of the curve for enriched water and that for the filtered water is almost identical with the one in the previous series. There is perhaps a little more irregularity in the enriched curve, and the whole is more flattened with more readings of higher value and fewer of more intermediate value. Only one of the twenty values of $\chi^{2}$ calculated from the $60 \mathrm{~min}$. readings is significant of itself, but the pooled result is clearly significant and the test for homogeneity is easily satisfied (Table XX). In fact there is less variation within this series than in the previous. A summary of the $\chi^{2}$ values is given.

Significantly more Calanus therefore swim up in the Ditylum-enriched water. The total mean percentages swimming up being $2 \mathrm{I} \cdot 7 \%$ in the filtered water and $29.5 \%$ in the enriched: both values a little higher than those with Skeletonema. The average concentration of Ditylum in the enriched water used was $527 \cdot 3$ cells $/ \mathrm{ml}$. or $0.53 / \mathrm{mm}^{3}$. 


\section{Group III. Gymnodinium I}

Evidence of the effect of the two diatoms having been found, Gymnodinium I, one of the organisms suspected of having a toxic effect, was next tried. With the possibility, after the hypothesis of animal exclusion, that Gymnodinium might suppress vertical migration to some extent, the control chosen for this series was an enriched water and not a filtered one. Twelve experiments of this nature were performed. The water was first passed through a Whatman no. I paper and one lot was enriched with the Gymnodinium culture and the other variously with Skeletonema, Chlamydomonas and a culture of mixed phytoplankton organisms grown by seeding the normal culture solution with a little raw sea water taken at the time of a diatom outburst. This culture contained diatoms and flagellates of several kinds including Skeletonema, Thalassiosira and a Nitzschia.

As may be seen from the graph in Text-fig. 3 (III), behaviour of the Calanus in the two sets of tubes was almost identical and closely resembled that in the enriched water in the two previous series. No tests of significance were applied and the total mean percentage swimming up in the enriched control was $20.0 \%$ and in the Gymnodinium-enriched water $20.2 \%$. The average concentration in the latter was 9.8 Gymnodinium cells $/ \mathrm{mm}^{3}:$ and in the former 47.4 cells $/ \mathrm{mm}^{3}$ of various kinds. It may be noted that the percentages swimming up are rather smaller than in the previous experiments.

\section{Group IV. Chlamydomonas sp.}

This series consisted of twelve experiments having filtered water in the control tube and water enriched with Chlamydomonas sp. culture in the experimental tube. Examination of the graph in Text-fig. 3 (IV) reveals the likelihood of some difference in behaviour between the two tubes, but this is by no means so clear as in the previous experiments. The control curve is similar in form to that obtained before, although it is somewhat flattened. Altogether there are sixty-two pairs of readings giving I24 values for each type of water. This is less than the numbers in groups I and II and may partly account for the difference in shape. The enriched curve lacks the definite peak characteristic of the previous curves, but nevertheless indicates a preponderance of higher readings.

When the test of independence is applied to the $60 \mathrm{~min}$. readings, four out of the twenty-four are shown to be significant, but one of these has the greater number swimming up in the control tube. Despite this, when the results are pooled and the test applied to the totals, their difference is shown clearly to be significant (Table XIX). The test for homogeneity is just satisfied and hence it is possible to place reliance on this result. The readings are, however, very variable and the difference in behaviour is neither as clearly marked nor as great as in the diatom experiments. The mean percentage swimming up 
in the control tubes was $14.4 \%$ and that in the enriched tubes $20 \cdot 2 \%$. The average concentration of Chlamydomonas employed was 73.7 cells $/ \mathrm{mm}^{3}$.

\section{Group V. Flagellate One}

Ten experiments were performed using water enriched with a culture of Flagellate One. This is one of the organisms which the toxicity experiments indicated might be harmful, but it was still compared with a control of Whatman no. I paper-filtered water. The total number of pairs of readings is sixty-two, this being equal to the number in the previous group. Inspection of the graph in Text-fig. $3(\mathrm{~V})$ reveals almost complete identity of behaviour between the two lots of water. Further, both curves closely resemble the control in the previous group, being only slightly flattened and having a few more readings of higher value. The mean percentages swimming up are $17.5 \%$ in the control and $17.2 \%$ in the enriched tubes. As a result of this no test for significance was applied. The average concentration of Flagellate One used in the first eight experiments was 94 cells $/ \mathrm{mm}^{3}$. In case this culture was not sufficiently dense to manifest any possible 'exclusion' effect the remaining two experiments were performed at a concentration of 209 cells $/ \mathrm{mm}^{3}$. There was, however, no apparent difference in behaviour, and it may be concluded that the presence of Flagellate One in no way affected the number of Calanus swimming up. The average concentration of cells employed in the whole series was II 7 cells $/ \mathrm{mm}^{3}$.

\section{Group VI. Gymnodinium II}

Eleven experiments were performed with Gymnodinium II, another of the flagellates shown to be toxic. The chosen control was water enriched with a mixed phytoplankton culture, grown, as before, by seeding with raw sea water. This culture consisted of almost pure Nitzschia closterium of the normal large form with a little Skeletonema and a few flagellates. In both the control and the experimental tubes the water was paper-filtered before being enriched. In one of the experiments only one pair of the four tubes was used, and as a result there are fifty-nine pairs of readings and five odd ones giving a total of I23 values each for the control and the experimental curves. Examination of the graph in Text-fig. 3 (VI) shows the form of the enriched control curve to be very similar to those obtained previously, including again the characteristic peak. The experimental Gymnodinium curve is also similar but is displaced now to the left and almost in the position of previous control curves. Two of the twenty-one values of $\chi^{2}$ show the difference between the two tubes to be significant. When the $60 \mathrm{~min}$. readings are pooled, however, the $\chi^{2}$ value does not even approach that required for significance (Table XIX). It seems therefore that, although fewer animals swim up in the Gymnodinium II enriched water, not enough stay down to give a significant difference, and the effect must be ascribed to chance. The total 
mean percentage swimming up in the diatom-enriched control was $15.9 \%$, and that in the Gymnodinium-enriched 13.6\%. The average concentration in the former was 5.6 cells $/ \mathrm{mm}^{3}$ and in the latter 9.5 cells $/ \mathrm{mm} .^{3}$.

The mean percentages swimming up are later calculated on the first four readings in every experiment and also on all the readings. Examination of Table XVIII suggests that, with Gymnodinium II, the difference between the two tubes increases with time. The pooled $\chi^{2}$ test was therefore applied both to the means of the first four readings and to the means of all the readings in each experiment, but neither of the values obtained showed a significant difference, although they were higher than for the 60 min. readings.

\section{Group VII. Oxyrrhis marina, Rhodomonas sp. and Nitzschia closterium}

Ten experiments were performed with the mixed culture of Oxyrrhis, Rhodomonas and Nitzschia, the Rhodomonas component of which is now thought to be toxic. The control was again chosen to be water enriched with mixed phytoplankton. This mixed culture consisted chiefly of Skeletonema, a naviculoid collected in chains, and Thalassiosira, with a little Chaetoceros and some flagellates. Altogether, seventy-one pairs of readings were taken giving I42 values for each of the cultures. The graph in Text-fig. 3 (VII) shows the behaviour of the animals in the two sets of tubes to have been almost identical. Both curves are typically those of enriched water but they lack the peak which is common in most of the earlier experiments and also include a greater number of higher values than previously. The curious dip in the centre of both curves at the value six is interesting. The total mean percentage swimming up in the enriched control was $29.7 \%$ and that in the Oxyrrhis-enriched water $30 \cdot 7 \%$. No tests were applied. The average concentration of diatoms in the enriched control water was $0.74 \mathrm{chain} / \mathrm{mm} .{ }^{3}$, a chain of average length being about four cells, together with some single cells. The concentration in the mixed experimental water was 6.4 cells of Oxyrrhis $/ \mathrm{mm}^{3}$, together with a few Nitzschia and a very few Rhodomonas cells. This fact may account in part for the absence of any depressant action on the vertical migration of the Calanus.

Group VIII. Mixed phytoplankton organisms

No clear difference having been found between filtered and enriched water in the last four series, it was considered desirable to confirm that this difference could still be demonstrated. Consequently, three experiments were performed with Whatman no. I paper-filtered water in the control tubes and similar water enriched with a mixed phytoplankton culture in the experimental tubes. This culture was grown as before, but was rather older and contained the normal large Nitzschia closterium, various small and large flagellates, a heliozoan and a large ciliate. Twenty-two readings were taken, giving forty-four values for each of the curves. Because of this low number 
the graph in Text-fig. 3 (VIII) is drawn to double the vertical scale used previously. A difference greater than any so far obtained between behaviour in the two waters is immediately apparent; and both curves closely resemble the early ones despite the higher numbers of animals swimming up. Even with so small a number of experiments the pooled $60 \mathrm{~min}$. results, when the test of independence is applied, are seen clearly to be significant (Table XIX). Although none of the six single $60 \mathrm{~min}$. readings are significant of themselves, the test for homogeneity shows them to be more uniform than any of the other series and the pooled result is therefore reliable. The total mean percentage swimming up in the filtered water was $15.0 \%$ and that in the enriched $30.8 \%$. The concentration of phytoplankton in the enriched water was 2 cells $/ \mathrm{mm}^{3}$.

\section{Group IX. Coscinodiscus concinnus}

The next five experiments used a culture of the large diatom C. concinnus. The control tubes contained Whatman no. I paper-filtered water and the experimental tubes water enriched with the Coscinodiscus culture. Twenty Calanus were again put into each tube. Thirty-three readings were made giving sixty-six values for each curve, and the graph in Text-fig. 3 (IX) is once more drawn to double the vertical scale. A preponderance of higher readings in the enriched water is again apparent, although the curve has a less pronounced and more rounded peak. This, however, accords well with the more flattened nature of the control curve (deriving from the greater number of higher readings) which, with a little extra irregularity to be expected from the smaller number of readings, otherwise closely resembles the early ones. It is particularly like the group IV and V control curves. Application of the test of independence to the $60 \mathrm{~min}$. readings gives three out of the ten as significant, but when it is applied to the pooled figures the whole series is shown to be so (Table XIX). The homogeneity test is satisfied although there is more variation between different readings than in series VIII. The total mean percentage swimming up in the control tubes was $23.0 \%$ and that in the enriched ones $36.0 \%$. Both these figures are the highest obtained for these two types of water in all the ten groups of experiments. The average concentration of Coscinodiscus in the enriched water was 22.4 cells $/ \mathrm{ml}$. or $0.02 / \mathrm{mm}^{3}$.

\section{Group X. Chlorella stigmatophora}

The last five experiments with Calanus utilized a culture of the non-motile alga Chlorella stigmatophora which has been shown to have toxic properties. The control chosen was paper-filtered water and thirty-two pairs of readings were taken, the graph in Text-fig. 3 (X) being drawn to the same scale as the previous two. The control curve is seen to be steeper and more like the first obtained, while the curve for the enriched water is very similar. The total mean percentages swimming up are $15.5 \%$ in the filtered water and II.5\% 
in the enriched, suggesting the possibility of a significant difference in behaviour between the two. This is not verified, however, and the test of independence demonstrates significance neither on the individual $60 \mathrm{~min}$. readings nor on the pooled figures. The average concentration of Chlorella in the enriched water was $226 \mathrm{cells} / \mathrm{mm} .{ }^{3}$. This is well below even the optimum found in the toxicity experiments and need not necessarily have any harmful properties.

The summary of the results in Table XVIII shows the mean percentages swimming up as calculated from $(a)$ the $60 \mathrm{~min}$. reading from each experiment, (b) the mean of the first four readings, and $(c)$ that of all the readings in each experiment. It can be seen that, generally, in each series as time goes on fewer animals swim up. This gradual decline in the proportion swimming up has been mentioned earlier as the reason for using the $60 \mathrm{~min}$. readings in assessing the significance and magnitude of the differences. It also emphasizes the importance of using animals caught as short a time as possible previous to the experiment, and it must probably be attributed to a general change in behaviour on being kept in the unnatural conditions of captivity.

The second change with time to be seen is that between successive series of experiments. There are considerable differences between what should be comparable figures in the different series. There are altogether seven series with filtered controls, and the proportions swimming up in these range from $23.0 \%$ in IX to $14.4 \%$ in IV. These particular experiments cover a period of just over 2 months and during that time, of course, considerable changes were taking place in the population of Calanus which was drawn on for the experimental animals. This factor, combined with the varying light and temperature conditions, probably accounts for this variation with time. Male, female, and stage V and occasionally stage IV Calanus were used just as taken in the townets; the plan being to test the reactions of a typical sample and not one particular stage. The stages and sexes present were determined from time to time, but the type of behaviour obtained could not be correlated with the composition of the sample. On account of this fluctuation with time it is perhaps unwise to make comparisons between the effects of different cultures. However, taking the percentage differences between the filtered control and the enriched experimental tubes in each of seven series, and the enriched control and experimental tubes in the other three, and arranging the figures in order of magnitude we obtain the scheme given in Table XX.

Each of the two columns in itself may be reliable in showing the relative degree to which the various cultures affect the number of Calanus swimming up. Relation of the one column to the other, however, presents difficulties. There are two alternatives. If the behaviour towards the enriched control water in each of the Gymnodinium I and II and the Oxyrrhis experiments is taken as identical with that in the mixed-phytoplankton-enriched experi- 
mental water in column I (i.e. the top value of I6); then the three cultures should be assigned the positive values of 16,15 and 14 as shown in brackets (i.e. 16 minus 0 , I and 2 respectively). This puts them at the top of the whole series as regards degree of effect on Calanus. If, however, the differences invoked by the first five (significant) cultures in column I are averaged and this figure of II is taken as the common denominator, then the three cultures must be assigned the values of + II, IO and 9 as underlined, and they should then be placed between Skeletonema and Ditylum in the whole series.

\section{Table XX. Comparison of the EfFects of Different CUltures IN THE Vertical ApParatus}

$\begin{gathered}\% \text { differences from } \\ \text { filtered water }\end{gathered}$
$S$ Mixed phytoplankton
I6

It is reasonable to suppose that different phytoplankton organisms may affect the behaviour of Calanus differently, but if this should be so it is not possible, with only the present evidence available, to state with any certainty the relative degree to which they act. It is clear, however, that more Calanus swam up in the presence of all of the phytoplankton organisms tested, except Flagellate One and Chlorella stigmatophora.

Besides the above series of experiments with Calanus, three each were done with decapod larvae and young Thysanoessa inermis. All but one of these were with a mixed phytoplankton culture similar to that used in group VIII above, the other being with Chlamydomonas. The control for each was Whatman no. I paper-filtered water. No significant difference in behaviour between the pairs of tubes could be detected in any of the experiments, either when tested individually, or when pooled. The number of animals swimming up was greater with the decapod larvae, but this derives from their marked positive reaction towards light. The total mean percentages swimming up in the three decapod larva experiments were $70.0 \%$ in the filtered control and $71.5 \%$ in the enriched water. In the three Thysanoessa experiments there were $17.9 \%$ in the control and $19.3 \%$ in the enriched water. Details of the individual results are given in Table XXI. 
Finally, five experiments were done using ten young Hemimysis lamornae in each tube of the apparatus in its original form. Owing to the marked movement of Hemimysis away from light these experiments were done in complete darkness in a constant temperature room and the animals counted from time to time by aid of a dim red lamp. All had ultra-filtered water in the control tube, and in the experimental tube similar water enriched in three experiments with Chlamydomonas and in two with Skeletonema culture. The

\section{TABle XXI. Results of EXPERIMENTS With CARCINUS Zoeas THYSANOESSA AND HEMIMYSIS IN THE VERTICAL APPARATUS}

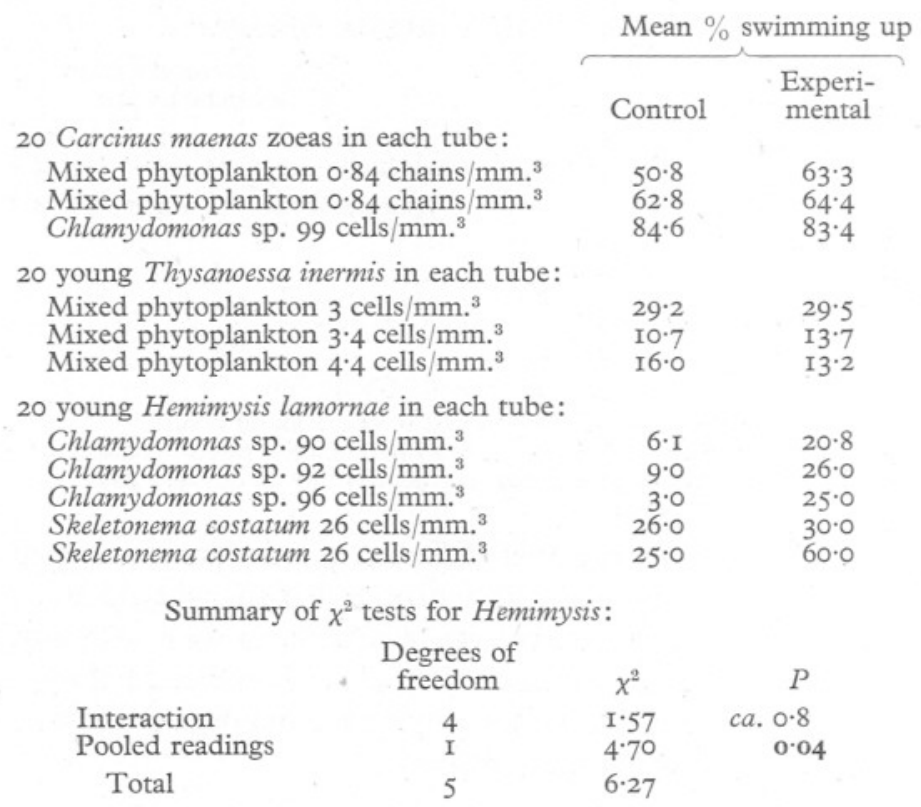

results have been assessed on the mean of all the readings in each experiment. When this is done no individual experiment is shown by the test of independence to be significant; but if all the results are pooled, the series is clearly so, and the test for homogeneity is satisfied (see Table XXI). The total mean percentages swimming up were $13.8 \%$ in the filtered and $32.0 \%$ in the enriched tubes. The average concentration of Chlamydomonas in the enriched water of the first three experiments was 93 cells $/ \mathrm{mm} .^{3}$ and of Skeletonema in the last two, 26 cells $/ \mathrm{mm}^{3}$.

\section{UNDERWATER OBSERVATIONS}

If the results of experimental work of the kind reported here are to be applied to a consideration of problems in the sea itself, it is important to know whether or not the behaviour of the animals in the various pieces of apparatus used 
resembles their behaviour under natural conditions. Underwater observations on the behaviour of some of the animals used have already been described (Bainbridge, I952). Ten more excursions were made in 1952, each involving descents in different places and giving a total of about $8 \mathrm{hr}$. underwater. In particular, the technique of swimming with foot-flippers and following animals while over deep water has been developed successfully. All the I95I observations on the spring brood of Calanus have been verified, although the 'upper zone' of I2 in. has seemed to be very much shallower this year, and there have been fewer animals in the deeper 'zone of migration'. In particular, the marked cessation of motion when the sun is covered has been noticed repeatedly. The whole sea gives a peculiar impression of idleness on such occasions. Besides the almost universal vertical swimming up and down, a more erratic movement has been seen once or twice. This is distinct from the bouncing along on the under surface of the water (which has also been seen again) and results in little or no forward movement at all. It is a violent dashing about in different directions, and is so rapid that it is not possible to tell how the animal is orientated or what limbs are being used. It is perhaps most adequately described as a 'caper' and seems to be rare. On one occasion also Calanus was seen swimming horizontally, deep in the body of the water with an uncommon sort of jerky side-to-side motion. Apart from these exceptions the continued occurrence of straight up and down swimming makes it certain that this is the form generally indulged in. It should perhaps again be noted that the downward swimming is invariably head-first down. Some Calanus from a deep townetting, when taken below in a jar and released, swam head-first downwards out of sight.

The collection in small swarms or clusters was again noticed, although these appeared smaller this year with rarely more than six animals in a group. One stage V Calanus was seen swimming with three adults, all circling round and round each other.

There were again many small copepods and young stages, but these were harder to observe because of the large amount of detritus repeatedly found in the water. A random sort of motion was prevalent, and even those swimming upwards appeared to do so in a jerky and 'kinetic' manner and then bounce away similarly (often towards the sun) along the under surface of the water. None were ever seen to go downwards in this way and it may perhaps be assumed that they gradually sink downwards to go jerkily up to the surface again after a certain time. Many seemed to hang head-first downwards but it was not possible to decide whether they sank in that position or whether they were preparing for swimming down.

Perhaps the most interesting observations concern three decapod larvae. The first two of these were megalopas both seen on 23 May. They were pale in colour and were rather small and were both swimming rapidly in a perfectly horizontal straight line, one about $2 \mathrm{ft}$. below the surface and the other about 
$3 \mathrm{ft}$. I was able to follow one for about I2 ft. and the other for $24 \mathrm{ft}$. There was no sign of deviation whatsoever, and the movement appeared most purposeful. They were both swimming roughly at $20^{\circ}$ to the right of the direction of the sun's rays. The third was a zoea seen on 3 July. This was large and probably Carcinus. It was about 4 or $5 \mathrm{ft}$. down and was swimming almost horizontally (slightly upwards) in a gently undulating line. (It is just possible that the undulation was the effect of my own movements, but this is very unlikely.) These three are the only decapod larvae so far seen.

Three young Thysanoessa inermis caught several days previously and used in one of the experiments were taken down and released separately from small jars. They all went down, one sinking, one swimming quite vigorously obliquely, and one head-first downwards.

Many ctenophores and medusae were seen on different occasions and these were usually quite randomly orientated. One large Bolinopsis was seen travelling horizontally, its large oral lobes streaming behind. Very many, roughly spherical, transparent bodies with six to ten small bubbles enmeshed in them were seen drifting along during one descent. One was taken in a breffit and proved to be Oikopleura in its house. Examined later in the laboratory, the house was found swarming with flagellates of all kinds and a few small diatoms and ceratia, etc. It seems likely that this enormous concentration of even the smallest flagellates was producing the tiny oxygen bubbles by photosynthesis. These must have buoyed up the house and affected the animal's movements in some way.

One descent was made purposely during rough weather. There was a great amount of wave action resulting in swirling about of medusae, ctenophores and a few small copepods. This movement went down to about Io ft. but diminished gradually. It was possible to follow some of the animals, but they were all being swirled about the whole time and no directive movement was observed.

\section{GENERAL DISCUSSION}

\section{EXPERIMENTS IN THE HORIZONTAL APPARATUS}

Considering first the results obtained with the horizontal apparatus it may safely be claimed that, under the conditions of the experiments, significant migrations by various animals into concentrations of phytoplankton have been demonstrated. This is particularly so with the mysids used, which swam into water enriched with cultures of Skeletonema, Thalassiosira, Biddulphia, Nitzschia and mixed diatoms and into cultures of the flagellates Chlamydomonas, Peridinium, Dicrateria, Flagellate $\mathrm{K}$, and Oxyrrhis. No marked movement into the diatoms Lauderia, Coscinodiscus and Eucampia was observed nor into the flagellates Syracosphaera and Exuviaella, but a movement 
away from Rhodomonas and Gymnodinium II was demonstrated. Various small copepods swam into cultures of the diatoms Nitzschia, Biddulphia and Thalassiosira, and positive results were also obtained with Artemia salina. It was not possible, however, to obtain consistent or intelligible results with either Calanus finmarchicus or with various decapod larvae.

There can be little doubt that these positive migrations are for the purpose of feeding; and, although this could not be demonstrated significantly, there was a greater incidence of them amongst starved animals than amongst fed ones. No experiments have so far been designed especially to throw light on the mechanism underlying the movement, but it seems likely that sometimes the effect of the phytoplankton may be mediated by substances dissolved in the water. This would not seem to be either concentration of carbon dioxide (which has the opposite effect), oxygen (which has no determinable effect) or $\mathrm{pH}$ (in which property the cultures do not differ appreciably from normal water), but more probably some kind of dissolved organic substance. Sometimes the actual physical presence of the diatoms is necessary.

Those flagellates invoking an avoiding reaction in the animals almost certainly do so through some substance dissolved in the water; this would seem both harmful and distasteful, although the deaths produced by Flagellate I2 seemed to result from the actual ingestion of the cells. The less consistent results with these cultures classed as 'toxic' are perhaps due to there being two conflicting reactions on the part of the animals-an avoidance of the water due to the distasteful substance in it and a movement into the actual concentration of cells for the purposes of feeding. If the feeding reaction is strong, due perhaps to starvation, a positive migration will result, if the avoiding reaction is strong, then a negative migration may. With the bacteria culture, of presumably little nutritive value to those animals tested, a consistent negative migration can be obtained: here clearly away from some dissolved organic substance.

In extent, both the positive and negative migrations seem to indicate an all-or-nothing reaction. The lumping together of those readings in any particular group which are classed as 'not-significant' but which might have been expected to be positive does not give any indication of a positive tendency but rather emphasizes the random nature of the distribution. It thus seems that if a positive or negative migration is to take place it does so without equivocation. In the mysids this may be connected with the shoaling reaction which they exhibit. The marked positive migrations into concentrations of ammonia are of particular interest on this account. Ammonia is one of the excretory products of these animals, and a tendency to congregate in water richer in ammonia would automatically act as an aggregating mechanism for them. Any small group of animals containing individuals circling round and round each other as they do, would excrete and develop its own cloud of ammonia round it. This would attract others and the whole would work on 
a snow-ball principle, gathering more and more animals into a bigger and bigger cloud. Such a sequence could conceivably take place most quickly in the presence of food and could constitute part of the mechanism behind the migrations in the tubes. Those shoals of mysids seen in aquaria and tanks must almost always be brought into being by uneven lighting conditions, but this cannot generally be so in nature and especially in the open sea. The shoals of euphausids seen by many observers (Hardy \& Gunther, 1935; Hart, see below), and the uneven distribution of small plankton animals reported by Barnes \& Marshall (I95I), and seen underwater by myself, cannot be dependent upon light. There may be many means by which animals keep together in swarms, such as sight or a rheotactic sense, but the possibility of some agent such as ammonia being involved in the mechanism in some species must be borne in mind.

Satisfactory and understandable results were not obtained with $C$. finmarchicus in the horizontal tubes and with the few samples of decapod larvae used. This would seem to be due to the different swimming habits of the various animals. As has been mentioned, it is not generally thought that members of the plankton possess powers of active migration of any consequence in the horizontal plane. The experimental results point to this being so with Calanus and it was for this reason that the vertical experiments were developed. This apparently fundamental tendency of Calanus to swim in a vertical plane is amply confirmed by the underwater observations.

This is not true of the other animals used in the horizontal tubes. The various mysids and Artemia appeared to behave perfectly naturally when indulging in their horizontal excursions. It is unfortunate that comparable animals could not be observed under water. The mysids are mostly nocturnal, when they cannot be seen, and in the daytime the euphausids are restricted to comparatively deep water. Those Thysanoessa released from captivity under water swam in straight lines with the long axis of the body pointing forwards but not horizontally, of course, as the initial response was to go away from the higher light intensity.

The decapod larvae that were seen were behaving exactly as might be expected if they are to fit into the group possessing powers of horizontal movement. The very variable results obtained with them are all the more puzzling. They may, of course, be due to the lack of any definite behaviour reaction towards the particular cultures used but they are nevertheless disappointing. It is interesting that six out of the twelve are significant one way or the other.

The surprising results with small copepods, where six out of six experiments showed the most definite movements into diatom cultures, may be accounted for by a third type of swimming behaviour. This is the random movement repeatedly observed under water and it is of course precisely such as would result in the rapid development of an uneven distribution of animals in the 
tube if there should be a tendency on their part to remain in one particular environment. Seen in the sea it is a vigorous movement, and canalized as it is in the tubes, it could result in quite a rapid horizontal movement. The experiments, nevertheless, demonstrate a marked preference by the animals for water rich in diatoms.

\section{EXPERIMENTS IN THE VERTICAL APPARATUS}

Considering the results obtained with the vertical apparatus it may again safely be claimed that, under the conditions of the experiments, significantly greater numbers of animals are shown swimming up in the presence of cultures of mixed phytoplankton, Gymnodinium I and II, Oxyrrhis, Coscinodiscus, Skeletonema, Ditylum and Chlamydomonas; while Flagellate One has no effect on the behaviour of Calanus, and Chlorella appears to depress the numbers swimming up. The control in some of these experiments was ultrafiltered water, but generally it was water filtered through a paper of the normal pore size. This was especially intended to allow minute flagellates and diatoms to pass through but to stop all the larger cells. The behaviour of the animals in the enriched water was therefore being compared with their behaviour in water containing a low concentration of food and not in entirely sterile water such as would not be found in the sea. In all the indoor experiments the intensity of light was such as to allow an average of about $25 \%$ of the animals to swim up. Under these conditions roughly twice as many did so in the enriched tubes as in the filtered, but as mentioned earlier some of the phytoplankton organisms used may have a greater effect than others.

The animals in the tubes appeared to resolve themselves into two distinct groups, the one swimming up and the other down. Those in the top compartment were generally in the upper half of this and, when Calanus, performed their 'hop-and-sink' movements there. Those in the lower compartment were generally in the lower half and some would be swimming head-first downwards and others doing the 'hop-and-sink'. It seems likely, therefore, that the short length of the tubes does not greatly affect the manifestation in the population they contain, of these two groups. There was, of course, interchange between the two but this was usually fairly rapid. In general, the swimming behaviour, especially of Calanus, bore a close resemblance to that seen in the sea.

The five experiments with young Hemimysis lamornae gave much greater numbers swimming up in the presence of Chlamydomonas and Skeletonema. Such young forms in nature are often found higher in the water and might be expected to show this sort of vertical movement in the tubes. The results with decapod larvae and Thysanoessa are more puzzling. The latter are very delicate and proved difficult animals from the experimental point of view. They are caught only in deep water and do not live at all well in captivity, especially in the unnatural confinement of the tubes. The decapod larvae 
showed their definite reaction to light by swimming constantly at the top of the tube and at the side nearest the oblique source of light. From this observation and their behaviour in jars and bowls while being picked out, there is no doubt that, had they been free to do so, they would have continued to swim along, horizontally near the surface and towards the source of light. It is possible that this overriding reaction towards light masked any effect on them of the phytoplankton, but it is also possible that they have no specific reaction under these circumstances.

No experiments have yet been performed expressly to search for the mechanism underlying this increase in upward migration in the presence of phytoplankton. The presence of plant cells must reduce the light intensity in the experimental tubes. The possibility of this being the direct stimulus is, however, rendered unlikely by the fact that the reduction in intensity in the Chlorella and Flagellate One experiments must have been as great, if not greater, than that in the rest of the series; and that the difference was still encountered in those experiments performed in the dark.

Experimental results such as those so far described must only be applied with the greatest diffidence to the problems found in nature itself. There are, however, certain extenuating circumstances in the present case. Foremost, in considering the problems of the inverse distribution of zooplankton and phytoplankton in the sea, is the difficulty of obtaining any other insight into the mechanisms involved. The most intensive sampling of plankton and the collection of physical data over a prolonged period of time from the same body of water (which may in the course of the months necessary for the study move hundreds of miles) is finally the only certain way in which the problem can be resolved. Such an investigation presents almost insuperable practical difficulties and certainly insuperable financial ones. Under these circumstances, and in view of the fact that such underwater observations as have been made confirm that the behaviour of the animals under experimental conditions is essentially like that in the sea, we may proceed to a projection of the experimental results into the field. During the process, however, the propriety of this operation must constantly be under review.

\section{The Size of Plankton Concentrations}

Before discussing the consequences of the occurrence in the sea of such migrations as have been shown experimentally, it is necessary to consider both the sizes of phytoplankton and zooplankton patches and the density of cells in the former.

\section{Phytoplankton}

There is a great body of evidence, collected by naturalists and seafarers, concerning the size and shape of patches of discoloured water which have 
been seen from on board ship. Scoresby, as early as I820, records long bands and streams of water apparently discoloured by diatoms; Darwin (I839) refers to bands and lanes discoloured by Trichodesmium, and Hornell (I908, I9I7) and Allen (I92I, I928, I938) refer especially to patches of red water caused by various flagellates. These observations are generally accompanied by estimates of the size of the areas, and maps may even be given, as in Suffren (I95I).

The second method of delimiting areas of high phytoplankton density involves intensive sampling with nets, and is very laborious. Savage (I930), Savage \& Hardy (I935), and Savage \& Wimpenny (I936) record the results of intensive sampling in the North Sea and give charts on which the geographical distribution and size of diatom patches are depicted. Hardy \& Gunther (1935) and Hart (1934) give the results of sampling work in the Antarctic and reveal similar sized concentrations.

Thirdly, the size of patches may be estimated from records taken with the Hardy continuous plankton recorder (Hardy, I936; Lucas, I940; Lucas \& Macnae, I94I).

These references make it clear that the occurrence of patches of both diatoms and flagellates is a normal state in the sea and that these patches, as was so aptly stated by Scoresby, are 'of very variable dimensions'. The lowest size estimate is 20 or 30 yards across but much longer, and the highest 200 miles by something of the order of 40 miles; while a general mean might be considered 3 or 4 miles by half a mile to a mile. There is abundant evidence that, although some patches are diffuse, they may often have quite distinct boundaries and may extend to considerable depths. The most interesting feature is undoubtedly their shape-almost invariably long and narrow. Even where precise dimensions are not given words such as 'bands', 'streaks', 'lanes', and 'stripes' frequently occur. It could most reasonably be expected that any patches would be roughly circular in shape or at any rate irregular; the former might arise from some one point of origin that was particularly well seeded with the species, and the latter in a more diffuse manner from several centres. The possible action of currents or of wind in influencing these shapes must of course be considered. Tidal streams and movements in coastal localities frequently result in the collection of flotsam and jetsam into lines, but this is unlikely to happen in the open sea. Wind action may be thought too superficial, but it is known that it can produce lines of convergence and upwelling orientated parallel with its direction (Langmuir, I938; Woodcock, I944) and that the circulations causing these lines may extend as far as $20 \mathrm{~m}$. down. Such an effect on a sufficiently large scale could influence the shape of patches but as so far demonstrated it appears to be too limited in extent. The possibility that grazing may be the cause will be considered later. 


\section{Zooplankton}

Although the evidence is far more limited, reference to Hardy \& Gunther (I935), Hardy (I936), Wimpenny (I936), and Rae \& Fraser (I94I) makes it clear that patches of zooplankton of the same order of size as those of phytoplankton are to be found in the sea. While recently, Barnes \& Marshall (I95I) have shown, by a statistical analysis of the results of a large number of small samples, that a number of small zooplankton organisms are often to be found in small swarms or clumps which are discontinuous in three dimensions. These patches are of a much smaller order than any previously demonstrated.

\section{The Density of Phytoplankton Concentrations}

Estimates of the density of cells in patches of diatoms can be found in Johnstone (I908), Gran (I9I2), and Allen (I9I9), who give, amongst others, values of $6.0,0.5$ and 0.46 cells $/ \mathrm{mm}^{3}$ for different organisms; while Harvey et al. (1935) give 45 cells $/ \mathrm{mm}^{3}$ for Skeletonema in Loch Striven. Flagellates and nanoplanktonic forms were not measured so exactly until later, when their great value as a source of food came to be realized. Gaarder \& Spärck (I932), Alvik (I934), and Gaarder (I938) give values for Norwegian oyster polls and fjords, and Cole (I939) values for water pumped into oyster tanks at Conway. These are of the order of $4-24$ cells $/ \mathrm{mm}^{3}$. The highest values for natural water appear to be those of Gross (Marshall, I947), who records $2400 / \mathrm{mm}^{3}$ of flagellates for the water of Sailean More, the arm of Loch Sween used as a control in some fertilization experiments. The comparable figure for diatoms is $\mathrm{I} \cdot 2 / \mathrm{mm} .^{3}$.

Figures for more open waters as in Savage et al. (I935-6) and Mare (I940) are generally lower, but Cole \& Knight-Jones (I949) give 5-70 organisms $/ \mathrm{mm}^{3}$ as general in the open sea. Estimates may be made from the larger hauls reported in Hardy \& Gunther (1935) and Hart (1942); these give figures of 0.50 and $0.42 \mathrm{cell} / \mathrm{mm} .^{3}$ respectively of diatoms, but in one instance 25 cells $/ \mathrm{mm}^{3}$ of Chaetoceros socialis in Deception Island Harbour. Davis (I948) records 60 cells $/ \mathrm{mm}^{3}$ of Gymnodinium brevis during a red-water bloom in the Gulf of Mexico.

It is thus clear that the density of phytoplankton organisms in the sea can, on occasions, almost equal the densities attainable in enriched culture media, but that generally it is much lower than this. At present our interest is in customary and regularly attainable maxima rather than average concentrations over wide areas. The former may be taken to be of the order of ro cells $/ \mathrm{mm} .^{3}$ for diatoms and roo cells $/ \mathrm{mm}^{3}$ for flagellates, although much higher figures than these may be found, as for instance $3 \mathrm{I} \cdot 6 \mathrm{cells} / \mathrm{mm} .^{3}$ for diatoms and $2400 / \mathrm{mm}^{3}$ for flagellates. Such concentrations must, however, be considered localized and of limited duration. More usual maxima would be 0.5 cells for diatoms and 50 cells $/ \mathrm{mm} .^{3}$ for flagellates. 
Those experiments performed at concentrations much higher than these are of especial interest in connexion with the exclusion hypothesis; as any excluding effect might be expected to be more marked at such concentrations. Those performed at concentrations more comparable with the ones found naturally are of especial interest in connexion with the new suggestion of feeding migrations.

\section{ConClusions}

Accepting then that patches of phytoplankton, of a comparable order of concentration to those in the tubes, occur commonly in the sea and that they are of the sizes indicated, what would be the consequences if the animals behave in the sea as they do in the various pieces of apparatus?

First it may be deduced that the hypothesis of animal exclusion cannot be of such universal application as was originally envisaged. The excluding effect was thought to be due to any concentration of phytoplankton (particularly diatoms) and to be of general and constant occurrence; affecting the vertical migrations of the great majority of animals in direct proportion to the concentration of plants. None of the diatoms used in the experiments has shown any toxic or excluding effect (with the exception of the highest concentration of Nitzschia). Such an excluding effect as has been shown is restricted to fairly high concentrations of two kinds of flagellates. This has, however, involved an active avoidance in the horizontal tubes, and what would amount in the sea to a passive avoidance, in the vertical tubes. It has been suggested by Hardy and by Lucas (personal communications) that exclusion might be mediated by only some specialized diatoms or flagellates. If that should be so and the responsible organisms should be of the sort found in the present work, then, in the mixed concentrations found in the sea, the excluding effect of the few would constantly be pulling in the opposite direction to the attractive effect of the majority of phytoplankton forms. There is insufficient evidence available on the distribution of flagellates in the sea for it to be stated firmly whether or not the widespread inverse relationships found could result from the wide occurrence of some particular toxic flagellate but this would seem to be a very unlikely mechanism. Indeed, Hart (I942) makes it clear that nanoplanktonic forms are not nearly so abundant in the Antarctic plankton as elsewhere and that the latter may often be almost purely diatom.

It would seem most consonant with the results to suggest that the exclusion mechanism as a means of producing the inverse relationship is of much more restricted occurrence. It could well be envisaged as operating where there are intense, often monospecific, blooms of some toxic flagellate, as for example Goniaulax. Under these conditions vertical migration up into the patch could easily be suppressed and there could also be an active horizontal migration away from the area by such animals as are equipped to do this. 
This denudation of animals would allow unsuppressed division of the flagellate and the development of an even more repellent and larger toxic area. The marked avoidance by mysids of the concentrations of bacteria is of interest in this context. One of the effects of toxic blooms is to cause a concentration of dead fish and other animals in the area (Gunther, Williams, Davis \& Walton Smith, 1948; Hornell, 1917). These decompose and must result in bacteria-rich water at least as concentrated as that used in the experiments. These regions will then be avoided by zooplankton forms, and this reaction should be classed as an exclusion effect.

Pure blooms of toxic organisms are however a rather specialized case, and such flowerings as do occur must frequently contain an admixture of attractive forms. Under these circumstances the reactions of animals must depend upon both the relative concentrations of the different forms and upon the physiological state of the animals themselves, and may be quite variable. Harvey (1937) has demonstrated what is apparently a selection in the feeding of Calanus. If this should occur in the sea, and acceptable forms should be taken in preference to harmful ones in such mixed patches, then the proportion of toxic organisms to others would be automatically and gradually increased until, perhaps, an almost monospecific bloom capable of excluding animals resulted. Such selective grazing could not account for blooms of organisms other than toxic or unaccepted forms.

The most normal condition in temperate seas, however, must be the occurrence of patches of phytoplankton which, upon all the evidence available, will be both acceptable and attractive to the animals. If the principles of migration which have become apparent during the experimental work obtain also in the sea, then there must be a gradual accumulation of animals in areas rich in phytoplankton. This will be effected in two ways, that is by vertical and by horizontal migration.

Hardy has developed the conception of, as he terms it, 'planktonic navigation'. The basis of this hypothesis is a variable vertical migration. It is well known that the water layers at different depths travel at different speeds and a vertically migrating animal must, if altering its behaviour in different areas and depths of water, automatically alter its position relative to a fixed point on the surface. Animals can thus by swimming up more, or less, in particular areas collect in these or avoid them. This valuable idea is fully dealt with in Hardy \& Gunther (1935, pp. 343-56). The principle does not require volition on the part of the animal and must, without any doubt, work continuously so long as the animals indulge in vertical migrations and so long as these alter according to the nature of the surrounding water. It is precisely such an alteration in behaviour which is demonstrated in the vertical experiments, but the alteration is directly opposite in sign to that originally postulated for the majority of animals by Hardy. The mechanism of navigation must still obtain, however, and must necessarily result in a gradual accumulation of 
animals in diatom-rich areas and a denudation of the neighbouring less rich areas. Indeed three species-Calanus simillimus, Drepanopus pectinatus and Antarctomysis maxima are cited by Hardy as behaving in this opposite manner and being attracted towards phytoplankton. These he regards, however, as interesting but special cases.

This migration into phytoplankton patches will proceed also in the horizontal plane. It is known that Meganyctiphanes norvegica is able to swim vertically upwards at about $\mathrm{I} 28 \mathrm{~m}$. $/ \mathrm{hr}$. for periods of several hours (Hardy \& Bainbridge, I95I) and to be capable of bursts of $27 \mathrm{I} \mathrm{m}$./ hr. (unpublished). These figures represent respectively I mile in I $3 \mathrm{hr}$. and in $6 \mathrm{hr}$., and if such speeds should be maintained horizontally in the sea they must necessarily have considerable effect on the spatial distribution of the animals concerned. Certainly no more effort, and probably less, would be involved in horizontal as compared with vertical swimming. Those animals then, already named, which are able to travel appreciable distances horizontally will gradually move up any gradients that may exist into the rich areas. It has been suggested that such a mechanism could take place only on a very small scale because of the lack of any orientating factor in the sea. If it should depend on random horizontal movements by the animals, then their area of search must of course be greatly reduced and the principle could not be of much importance relative to some of the large patches that we know to exist. If, however, there is some orientating factor which will draw the animals on constantly in one direction, then they will cover a much greater area, and their movements relative to large patches will become of importance. Such an orientating factor may well be found, in the northern and southern latitudes, but not in the equatorial ones, in the sun. Although daily traversing the sky from east to west there will always be a component in its light which is predominantly from either the north or the south depending upon the hemisphere. Such a horizontally directive component, even if very small, could in the otherwise uniform sea, impose a general trend in one particular direction on the aimless excursions of animals. This would greatly increase their exploratory powers and their chances of finding, and remaining in, areas rich in phytoplankton would consequently be increased. The strange little piece of swimming behaviour observed in those small copepods that came up to the surface and then moved along horizontally may easily be a representation on a small scale of the sort of behaviour we are envisaging. In any case, whether directive or random movement be operative, there are patches of phytoplankton of sizes conveniently within the reach of all zooplankton forms.

This gradual accumulation of animals in the rich areas will result in an increase in the intensity of grazing there. This will have little effect on the actual concentration of plant cells present until the rate of removal exceeds the rate of increment by cell division. When this happens the whole relation- 
ship will change rapidly. In the matter of a day or two, or even hours, depending upon the numbers of animals present, the plant cells will be grazed down to a negligible number.

In the meantime, the neighbouring areas of sea will, by the departure of the zooplankton, have acquired those conditions necessary for a fresh outburst of diatoms to take place. This will be more or less uninhibited and will quickly
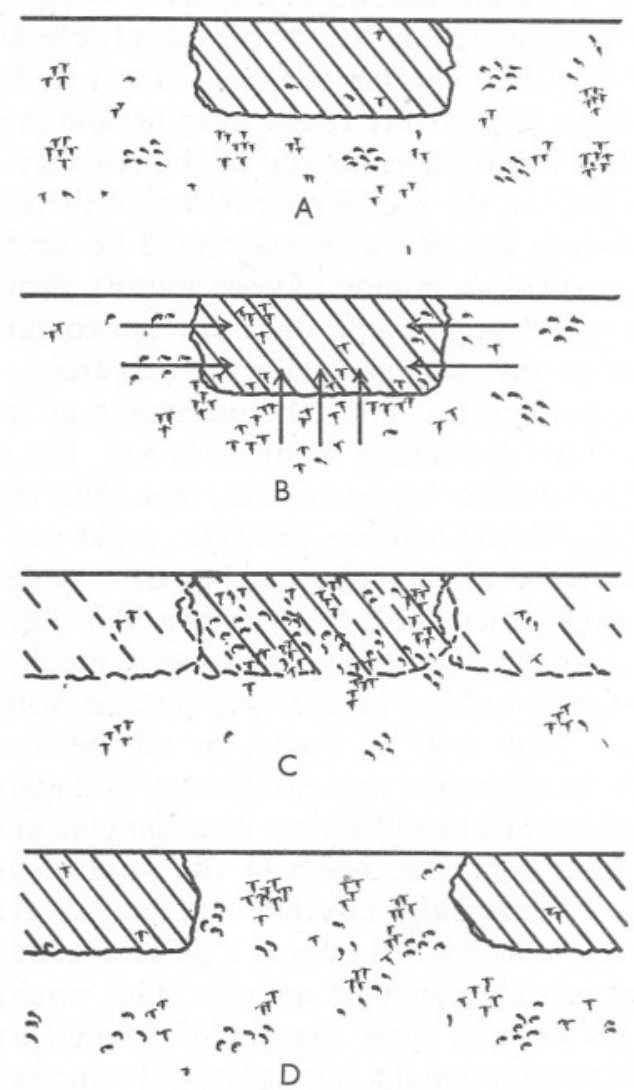

Text-fig. 4. Scheme of grazing and migration cycle. A, initial state with inverse relationship $\mathrm{B}$, start of migration with some grazing; C, completion of migration and heavy grazing; $\mathrm{D}$, reversal of initial state and return to inverse relationship. Oblique hatching represents concentrations of phytoplankton.

reach high concentrations. The situation will thus be reversed and the animals will again be inversely distributed in relation to the plants but a new cycle of migration, grazing and growth will immediately be initiated. This is shown diagrammatically in Text-fig. 4 .

The speed with which this cycle of events will take place must depend on several variables including the densities of animals and plants, the speeds of 
migration, and the rate of division of the plants and of grazing by the animals. These are all factors to which definite values can be ascribed and it should -eventually be possible to describe such a cycle mathematically. This is not however within the scope of the present work. The only necessary assumption is that the rates of migration must not be too high as compared with the rate of division of the phytoplankton, or otherwise a perfectly uniform sea would result and any increase in phytoplankton would be eaten down before developing noticeably. The small, when regarded absolutely, but relatively large difference in the proportions swimming up in the vertical tubes would seem in this connexion to be reasonable in extent; while an all or nothing reaction with a threshold value of a fairly high phytoplankton concentration would suffice as regards horizontal movements. Further, if there should be a lag in the movements of the animals then, starting from the slightest inequalities in distribution, these will oscillate with gradually increasing amplitude until the largest possible differences come into being.

The evidence at present available would seem to be more in accord with this hypothesis than with the others so far put forward. The inverse relationship in the sea is never absolute, often not clearly marked and sometimes completely reversed. This latter state, where high concentrations of both animals and plants occur in the same area, cannot be explained on the exclusion hypothesis, nor would it be expected on a simple theory of grazing. A dense concentration of animals and a dense concentration of plants are mutually incompatible entities. Their occurrence together must produce a situation of instability. The possibility of their having grown up together is surely much less likely than that of the animals having only recently come into the area, and being at that point in the cycle immediately prior to overcoming the rate of division of the plant cells. This state of distribution, the more common reverse one, and the intermediate ones can all be accounted for on a combination of migration and grazing, as can also the various experimental observations.

Hardy \& Gunther (I935) found three species directly correlated with high concentrations of phytoplankton. Two of these (Calanus simillimus and Drepanopus pectinatus) were species which showed a most marked vertical migration, coming up to the surface before, and remaining there longer than, most other forms; and the third was a mysid (Antarctomysis maxima). It would now seem possible that this positive correlation occurred because these three forms are such active swimmers and have well-developed powers of navigation and migration. They can perhaps collect in regions of high phytoplankton density more readily than other forms and, their total numbers being insufficient to produce a marked grazing effect, they would therefore more often be found directly correlated with the plants than other forms.

Lucas's (1936) results, which might at first seem incompatible with the new hypothesis, can in fact be interpreted quite simply. He found a greater 
number of animals visible in the unshaded portion of half-shaded tubes when no diatoms were present than when the water was rich in diatoms. This he ascribes to the production by the diatoms, in sunlight, of some substance distasteful to the animals and the consequent avoidance by the latter of this part of the tube. An equally reasonable explanation is that the mysids, generally negatively phototropic in captivity (Tattersall \& Tattersall, I95I), swim away from the light in the enriched tubes where they are well fed, while in the unenriched tubes they are continuously making excursions out of the shaded part in search of food and consequently more are counted here.

Fleming (1939) shows mathematically that any large increase in grazing associated with an increase in the number of grazers will reduce the diatom population very rapidly and that similarly the development of dense diatom populations can only take place when the grazing is less than the production of new cells. He regards such increases and decreases generally as due to reproduction and death of the animals but remarks that similar results would be obtained by 'the intrusion of an outside population'.

When currents in a particular region are sweeping on undeflected for large distances, the theoretical effect of navigation as postulated by Hardy is to form the animals into long straight lines (Hardy \& Gunther, I935, p. 35I). This aggregation he takes to occur in regions of poor phytoplankton, but the argument can as well apply to the formation of long patches or belts either within, or more probably at first, along the edges of regions rich in phytoplankton. These concentrations of animals will imprint, by grazing, a similar banded pattern upon the phytoplankton; both eating out bands and leaving bands of water free for fresh outbursts. Such a system, distorted and broken occasionally by cross-winds, could account for the prevalence in oceanic areas of long narrow patches of phytoplankton which have been observed so repeatedly.

The essential feature of this migration hypothesis is the dynamic and fluctuating property which it attributes to distributions in the sea. Harvey's hypothesis of grazing pictures the whole process as rather rigid and automatic with concentrations of zooplankton growing and breeding in one body of sea and naturally precluding any outburst of diatoms there; while this will occur unrestrictedly in other areas. Hardy's hypothesis pictures a more or less rigid pattern of phytoplankton distribution imposing, by its exclusive powers, an inverse pattern upon the animals. The migration hypothesis, on the other hand, pictures a constant fluctuation and movement of both animals and plants relative to each other; the former constantly searching for the latter in an endless cycle of horizontal and vertical migrations, and the latter constantly flowering up when the pressure of grazing is eased. Such a picture, although less precise, would seem more likely to be true of living organisms in an environment so unrestrictive to movement as the sea.

The attribution to some of the commonly termed 'planktonic' animals, of 
considerable powers of horizontal migration need cause little concern. If a definition such as Bigelow's ${ }^{1}$ is accepted, then it is clear that these animals should simply be referred to the already existing category of nekton.

The idea of a directive swimming by plankton animals is by no means new. No less an authority than Gurney says (1924, p. 39): 'It seems likely that the larvae of Decapods and Euphausids are not so much at the mercy of the currents as might be supposed. It is not very unusual to find swarms of the larvae of one species in different stages of development, which seems to indicate a power of keeping together from hatching onwards, or of collecting in a suitable locality'; and 'Some species seem to have decided preferences for certain regions, if one may judge from the behaviour of the British species of Leander. Quite early stages of the larvae are taken singly or in small numbers near Plymouth Sound, but later stages are exceedingly rare in in-shore waters, although the adults are abundant. But as the time for transformation approaches, the larvae seek the shore....Larvae are no doubt frequently carried by currents out of their normal habitat, and Foxon has given the examples of Porcellana macrocheles and Calappa marmorata which are sometimes so carried by the Gulf Stream to the shores of New England, but I believe that this is exceptional, and that the larvae for the most part have power to control their movements.'

Russell (I927) speaks of encountering a swarm of Corystes zoeas which was plainly visible from the ship; while 6 weeks later a swarm of Corystes megalopas was encountered in the same locality, and he considers the possibility of it being the same one. The megalopas, interestingly enough, were restricted to an area rich in Rhizosolenia. Macdonald (1927), in an account of the food and habits of Meganyctiphanes norvegica, speaks of congregations of both this form and Thysanoessa raschii in the Cumbrae Deep, on occasions when there was much detritus in the water, and also when Calanus finmarchicus was abundant. The euphausids were feeding upon these two, and the clear implication is that they migrated to and remained swarming in this place only while the food was available. Macdonald says he is not suggesting that the vegetable detritus or Calanus attracted the Meganyctiphanes to this particular locality, but the possibility of this having occurred is more plausible than that of their concurrence being fortuitous. He reports Bigelow as giving an account of a similar swarming of Meganyctiphanes in the neighbourhood of a sardine factory from which refuse was being dumped.

Euphausids can, especially in the Antarctic, be completely herbivorous. The likelihood of their migrating into areas rich in diatoms is surely high, and a similar activity on the part of other vigorously swimming forms also

\footnotetext{
1 Bigelow (I924): 'By plankton we understand all such forms as float or swim freely in the water, but which, however active, are unable to carry out voluntary horizontal journeys of any extent, though certain of them perform considerable vertical migrations under the directive influence of sunlight or of some other physical stimulus.'
} 
plausible. This, combined with the preferential vertical migration of the remaining organisms into areas rich in food, must automatically result in such a cycle as we have postulated; and the continued occurrence of this would give just such a degree of inverse relationship to catches of animal and plant plankton as is, in fact, found in nature.

\section{SUMMARY}

An apparatus in which it is possible to observe the horizontal migrations of zooplankton in gradients of phytoplankton is described, and an account given of its use in experiments involving various organisms. A preliminary search for toxic organisms is also described.

The experiments comprise a demonstration of a migration by various animals into concentrations of the diatoms Skeletonema, Thalassiosira, Biddulphia, Nitzschia and various mixed cultures and the flagellates Chlamydomonas, Peridinium, Dicrateria, $\mathrm{K}$, and Oxyrrhis. Cultures of Rhodomonas and Gymnodinium II are found to produce the opposite effect, and no reaction towards Lauderia, Coscinodiscus, Eucampia, Syracosphaera and Exuviaella could be shown. Results with bacteria cultures and various inorganic gradients are also discussed.

A second apparatus in which it is possible to observe the vertical migrations of zooplankton in the presence and absence of phytoplankton is also described, and an account given of experiments in it involving various organisms.

The experiments comprise a demonstration that greater numbers of animals swim up in the presence of mixed phytoplankton cultures, Coscinodiscus, Skeletonema, Ditylum, Chlamydomonas, Gymnodinium I and II and Oxyrrhis than in unenriched water. Flagellate One has no effect and Chlorella possibly depresses the number swimming up.

Under-water observations on the swimming movements of some of the animals used are described.

The possible application of the observations towards resolving the problem of the inverse distribution of phytoplankton and zooplankton in the sea is discussed, and the hypothesis is proposed that this may be accounted for by a combination of migration and grazing. It is considered that plankton animals must migrate both horizontally and vertically into patches of phytoplankton and, when present in sufficient numbers, graze these down very quickly. In the meantime fresh growths of phytoplankton will have occurred in neighbouring areas of sea now devoid of animals and the inverse relationship will be re-established. This changing cycle of distribution is thought to be continuous. 


\section{REFERENCES}

Allen, E. J., I9I9: A contribution to the quantitative study of plankton. Fourn. Mar. Biol. Assoc., Vol. I2, pp. I-8.

Allen, E. J. \& Nelson, E. W., I9ro. On the artificial culture of marine plankton organisms. Fourn. Mar. Biol. Assoc., Vol. 8, pp. 42 I-74.

ALlen, W. E., I92I. Preliminary statistical studies of marine phyto-plankton of the San Diego region, California. Special Publ. Bernice P. Bishop Museum, No. 7, pp. $537-54$.

- I928. Quantitative studies on inshore marine diatoms and dinoflagellates collected in southern California in 1924. Bull. Scripps Inst. Oceanog., Vol. I, No. 15, pp. 347-56.

- 1938. Red water along the west coast of the United States in 1938. Science, Vol. 88, pp. 55-6.

Alvik, G., I934. Plankton-Algen norwegischer Austernpollen. I. Systematik und Vorkommen der Arten. Bergens Museums Arbok, Naturv. rekke, No. 6, pp. I-47.

BAINBRIDGE, R., I949. Movement of zooplankton in diatom gradients. Nature, Vol. I63, pp. 9I0-II.

- 1952. Underwater observations on the swimming of marine zooplankton. Fourn. Mar. Biol. Assoc., Vol. 31, pp. I07-12.

BARNES, H. \& MARShall, S. M., I95I. On the variability of replicate plankton samples and some applications of 'contagious' series to the statistical distribution of catches over restricted periods. Fourn. Mar. Biol. Assoc., Vol. 30, pp. 233-63.

Bigelow, H. B., I924. Plankton of the offshore waters of the Gulf of Maine. Bull. Bureau Fisheries, Vol. II, Pt. II, 509 pp.

BRONGERSMA-SANDERS, M., I948. The importance of upwelling water to vertebrate paleontology and oil geology. Kon. Ned. Ak. Wet., Verh. Afd. Nat. (Tweede Sectie), D r, 45, No. 4, pp. I-II2.

Cole, H. A., 1939. Further experiments in the breeding of oysters (Ostrea edulis) in tanks. Min. Agric. Fish., Fishery Invest., Ser. II, Vol. I6, No. 4, pp. I-47.

Cole, H. A. \& KnIGHT-Jones, E. W., I949. Quantitative estimation of marine nannoplankton. Nature, Vol. I64, pp. 694-6.

DARWIN, C., I839. A naturalist's voyage. Fournal of the researches into the natural history and geology of the countries visited during the voyage of H.M.S. 'Beagle' round the world. Under the command of Capt. FitzRoy, R.N., $55 \mathrm{I}$ pp. London, John Murray, I889 (fourth edition).

DAvis, C. C., 1948. Gymnodinium brevis sp.nov. A cause of discoloured water and animal mortality in the Gulf of Mexico. Bot. Gazette, Vol. Io9, No. 3, pp. 358-60.

Fleming, R. H., I939. The control of diatom populations by grazing. fourn. Cons. Int. Explor. Mer, Vol. 14, pp. $210-27$.

FULLER, J. L., I937. Feeding rate of Calanus finmarchicus in relation to environmental conditions. Biol. Bull. Woods Hole, Vol. 72, pp. 233-46.

GAARDER, K. R., I938. Phytoplankton Studies from the Tromso District I930-3I. Tromso Museums Arshefter Naturh. avd Nr. I I, Vol. 55 (1932), No. I, pp. I-I 59.

GAARDER, T. \& SPÄRCK, R., I932. Hydrographisch-biochemische Untersuchungen in norwegischen Austern-Pollen. Bergens Museums Arbok, 1932, Naturv. rekke, Nr. I, pp. I-I44.

GAUld, D. T., I95I. The grazing rate of planktonic copepods. Fourn. Mar. Biol. Assoc., Vol. 29, pp. 695-706.

Gran, H. H., I9I2. The plankton production of the north European waters in the spring of I9I2. Bull. Planktonique, pp. 5-142. 
Gunther, G., Williams, R. H., Davis, C. C. \& Walton Smith, F. G., I948. Catastrophic mass mortality of marine animals and coincident phytoplankton bloom on the west coast of Florida, November 1946 to August 1947. Ecol. Monographs, Vol. I8, pp. 309-24.

Gurney, R., I924. Crustacea, Pt. IX. Decapod Larvae. British Antarctic ('Terra Nova') Exp. 1910. Natural History Rep. Zoology, Vol. 8, pp. 37-202.

HARDY, A. C., I936. Observations on the uneven distribution of the oceanic plankton. Discovery Rep., Vol. II, pp. 5II-38.

HARDY, A. C. \& BAINBRIDGE, R., I95I. Vertical migration of plankton animals. Nature, Lond., Vol. I68, pp. 327-28. (Substance of a paper read at the British Association.)

HaRDY, A. C. \& Gunther, E. R., I935. The plankton of the South Georgia whaling grounds and adjacent waters, I926-27. Discovery Rep., Vol. II, pp. I-456.

HaRdy, A. C. \& Paton, W. N., I947. Experiments on the vertical migration of plankton animals. Fourn. Mar. Biol. Assoc., Vol. 26, pp. 467-526.

HART, T. J., I934. On the phytoplankton of the south-west Atlantic and the Bellingshausen Sea, I929-3I. Discovery Rep., Vol. 8, pp. I-268.

- 1942. Phytoplankton periodicity in Antarctic surface waters. Discovery Rep., Vol. 2I, pp. 26I-356.

Harvey, H. W., I934. Annual variation of planktonic vegetation, I933. Fourn. Mar. Biol. Assoc., Vol. 19, pp. 775-92.

— 1937. Note on selective feeding by Calanus. Fourn. Mar. Biol. Assoc., Vol. 22, pp. 97-100.

Harvey, H. W., Cooper, L. H. N., Lebour, M. V. \& Russell, F. S., I935. Plankton production and its control. Fourn. Mar. Biol. Assoc., Vol. 20, pp. 407-4I.

HoRNell, J., I908. The results of a fishery cruise along the Malabar coast and to the Laccadive islands in 1908. Madras Fishery Invest. Bull., No. 4, pp. 71-126.

- 1917. A new protozoan cause of widespread mortality among marine fishes. Madras Fishery Invest. Bull., No. II, Rep. No. 2, pp. 53-66.

Johnstone, J., I908. Conditions of Life in the Sea, $332 \mathrm{pp}$. Cambridge.

LANGMUIR, I., I938. Surface motion of water induced by wind. Science, Vol. 87, pp. II9-23.

LUCAS, C. E., I936. On certain interrelations between phytoplankton and zooplankton under experimental conditions. Fourn. Cons. Int. Explor. Mer., Vol. I I, pp. $343-62$.

I940. Ecological investigations with the continuous plankton recorder: the phytoplankton in the southern North Sea, 1932-37. Hull Bull. Mar. Ecol., Vol. I, pp. 73-I70.

— 1947. The ecological effects of external metabolites. Biol. Rev., Vol. 22, pp. $270-95$.

- I949. External metabolites and ecological adaptation. Symposia of the Soc. for Exp. Biol. No. III. Selective Toxicity and Antibiotics, pp. 336-56.

LuCAS, C. E. \& MACNAE, W. I94I. Continuous plankton records. Phytoplankton in the North Sea, 1938-1939, Part I. Diatoms. Hull Bull. Mar. Ecol., Vol. 2, pp. I-50.

MACDONALD, R., I927. Food and habits of Meganyctiphanes norvegica. Fourn. Mar. Biol. Assoc., Vol. 14, pp. 753-84.

MARE, M. F., I940. Plankton production off Plymouth and the mouth of the English Channel in 1939. Fourn. Mar. Biol. Assoc., Vol. 24, pp. 46I-82.

Marshall, S. M., I947. An experiment in marine fish cultivation: III. The plankton of a fertilised loch. Proc. Roy. Soc. Edinb., B, Vol. 43, Pt. I (No. 3), pp. 2I-33. 
RAE, K. M. \& Fraser, J. H., I94I. The copepoda of the southern North Sea I9321937. Hull Bull. Mar. Ecol., Vol. I, pp. I71-238.

RusseLL, F. S., I927. The vertical distribution of marine macroplankton. V. The distribution of animals caught in the ring trawl in the daytime in the Plymouth area. Fourn. Mar. Biol. Assoc., Vol. I4, pp. 557-608.

SAVAGE, R. E., I930. The influence of Phaeocystis on the migrations of the herring. Min. Agric. Fish., Fishery Invest., Ser. II, Vol. I2, No. 2, pp. I-I4.

SAvage, R. E. \& Hardy, A. C., 1935. Phytoplankton and the herring. Part I. 192 I-1932. Min. Agric. Fish., Fishery Invest., Ser. II, Vol. I4, No. 2 (1934), pp. I-73.

Savage, R. E. \& Wimpenny, R. S., I936. Phytoplankton and the herring. Part 2, I933 and I934. Min. Agric. Fish., Fishery Invest., Ser. II, Vol. I5, No. I (1936), pp. I-88.

SCOREsby, W., I820. An Account of the Arctic Regions with a History and Description of the Northern Whale-fishery. 3 vols. Edinburgh.

Steemann Nielsen, E., I937. On the relation between the quantities of phytoplankton and zooplankton in the sea. Fourn. Cons. Int. Explor. Mer., Vol. I2, pp. I47-54.

Suffren, J. R., I95I. Discoloured water, East China Sea. The Marine Observer, Vol. 21, No. I53, p. I55.

Tattersall, W. M. \& Tattersall, O. S., I95I. The British Mysidacea, 460 pp. London.

WIMPENNY, R. S., 1936. The distribution, breeding and feeding of some important plankton organisms of the south-west North Sea in 1934, Part I. Min. Agric. Fish., Fishery Invest., Ser. II, Vol. I5, No. 3, pp. I-53.

WoodCOCK, A. H., I944. A theory of surface water motion deduced from the windinduced motion of the Physalia. Fourn. Mar. Res., Vol. 5, pp. 196-205. 


\section{Appendix I. List of Phytoplankton ORganisms USED}

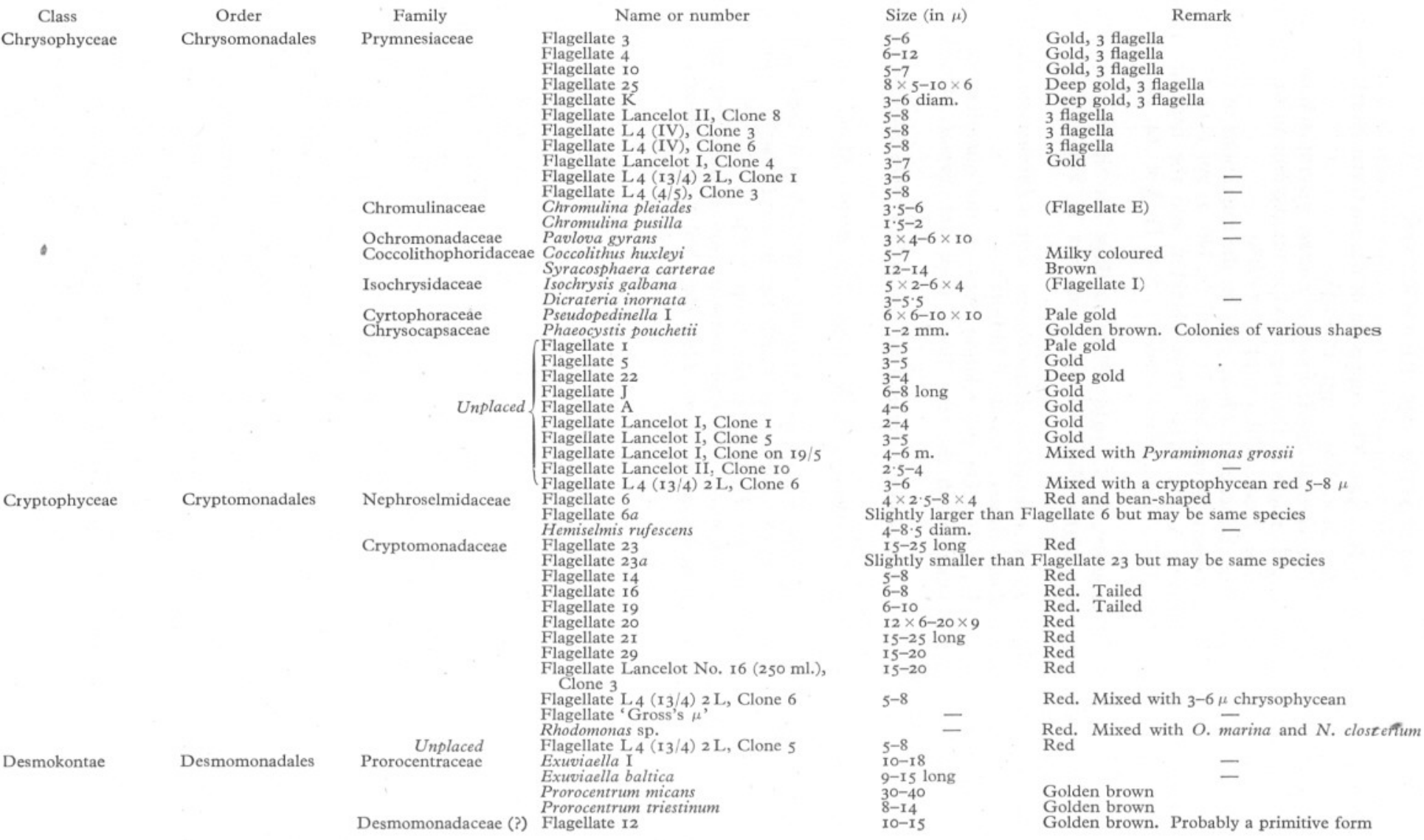


Class

Dinophyceac

Chlorophyceas

Bacillariophyceae
Order

Gymnodiniale

Pronoctilucacea

Gymnodiniaceae

Peridiniales
Volvocales

Chlorococcales

Ulotrichales
Centrales

Chlamydomonadace

Polyblepharidaceae

Chlorellaceae

Ulotrichaceae

aceae

Biddulphiaceac

Chaetoceraceae
Fragilariaceae

Naviculaceae
Nitzschiaceae

Naviculaceae
Nitzschiaceae

Pennales

APPENDIX I (continued)

$\quad$ Name or number
Oxyrrhis marina
Gymnodinium I
Gymnodinium II
Massartia rotundata
Peridinium trochoidium
Chlamydomonas II
Platymonas apiculata
Pyramimonas sp.
Chlorella stigmatophora
Stichococcus I
Coscinodiscus concinnus
Skeletonema costatum
Thalassiosira gravida
Thalassiosira nordenskioldii
Lauderia borealis
Biddulphia sinensis
Ditylum brightwellii
Eucampia zoodiacus
Chaetoceros decipiens
Licmophora lyngbyei
Naviculoid lysterium
Nitzschia closterium
Nitzschia closterium (forma minutissima)
Nitzschia seriata

Size (in $\mu$ )

10-30

$6-20$
$6-22$

$\mathrm{I}-2-14$
$2 \mathrm{O}-30$

$6 \times 4-12 \times 8$

$7-10$
$6-8$
$4-6$

$3-5 \times 2$. Rods

150-450 diam.

7-16 diam.

12-43 diam.

$34-38$ diam.

x 20-240 long

$25-60$ diam.

$25-73$ broad
$12-78$ broad

$50-75$ long
c. 100 long

$20-90$ long

I00 $\times 6$
Remarks

Colourless. Mixed with Rhodomonas sp. and N. closterium

Brown

Reddish brown

Green

Probably S. cylindricus Butcher

All the diatom cultures appear brown

to a greater or lesser extent

Containing some of the 'tri-radiate' form

\section{APPENDIX II. LIST OF ZoOPLANKTON ORganisMS USED}

Crustacea

$$
\begin{aligned}
& \text { Branchiopoda } \\
& \text { Anostraca } \\
& \text { Artemia salina. }
\end{aligned}
$$

Copepoda

Eucopepoda

Calanus finmarchicus, Eurytemora hirundoides, etc.

Harpacticoida

Tigriopus fulvus.

Malacostraca

Hemimysis lamornae, Praunus neglectus, P. flexuosus, Neomysis integer, Mesopodopsis slabberi.

Euphausiacea

Thysanoessa inermis.

Decapoda

Various larvae. 